\title{
A Sodium-Pump-Mediated Afterhyperpolarization in Pyramidal Neurons
}

\author{
Allan T. Gulledge, ${ }^{1,2}$ Sameera Dasari, ${ }^{1}$ Keita Onoue, ${ }^{1}$ Emily K. Stephens, ${ }^{1,2}$ J. Michael Hasse, ${ }^{1,2}$ and Daniel Avesar ${ }^{1,2}$ \\ ${ }^{1}$ Department of Physiology and Neurobiology and ${ }^{2}$ Program in Experimental and Molecular Medicine, Geisel School of Medicine at Dartmouth, Lebanon, \\ New Hampshire 03756
}

\begin{abstract}
The sodium-potassium ATPase (i.e., the "sodium pump") plays a central role in maintaining ionic homeostasis in all cells. Although the sodium pump is intrinsically electrogenic and responsive to dynamic changes in intracellular sodium concentration, its role in regulating neuronal excitability remains unclear. Here we describe a physiological role for the sodium pump in regulating the excitability of mouse neocortical layer 5 and hippocampal CA1 pyramidal neurons. Trains of action potentials produced long-lasting ( $\sim 20 \mathrm{~s})$ afterhyperpolarizations (AHPs) that were insensitive to blockade of voltage-gated calcium channels or chelation of intracellular calcium, but were blocked by tetrodotoxin, ouabain, or the removal of extracellular potassium. Correspondingly, the AHP time course was similar to the decay of activity-induced increases in intracellular sodium, whereas intracellular calcium decayed at much faster rates. To determine whether physiological patterns of activity engage the sodium pump, we replayed in vitro a place-specific burst of 15 action potentials recorded originally in vivo in a CA1 "place cell" as the animal traversed the associated place field. In both layer 5 and CA1 pyramidal neurons, this "place cell train" generated small, long-lasting AHPs capable of reducing neuronal excitability for many seconds. Placecell-train-induced AHPs were blocked by ouabain or removal of extracellular potassium, but not by intracellular calcium chelation. Finally, we found calcium contributions to the AHP to be temperature dependent: prominent at room temperature, but largely absent at $35^{\circ} \mathrm{C}$. Our results demonstrate a previously unappreciated role for the sodium-potassium ATPase in regulating the excitability of neocortical and hippocampal pyramidal neurons.
\end{abstract}

\section{Introduction}

Periods of action potential generation in pyramidal neurons in the neocortex and hippocampus produce long-lasting afterhyperpolarizations (AHPs) that are thought to involve several ion- and/or voltage-dependent potassium conductances. Early components of the AHP, including the "fast" $(<10 \mathrm{~ms})$ and "medium" ( $<100 \mathrm{~ms}$ ) AHPs, involve a combination of calcium- and voltage-dependent potassium conductances (Storm, 1987, 1989; $\mathrm{Gu}$ et al., 2005; Tzingounis and Nicoll, 2008). Slower components of the AHP include a calcium-dependent "slow" ( 1-2 s) AHP (Alger and Nicoll, 1980; Hotson and Prince, 1980; Brown and Griffith, 1983; Madison and Nicoll, 1984; Lancaster and Adams, 1986; Schwindt et al., 1992) and a longer-lasting (many seconds) "late slow" AHP that is sodium, rather than calcium, dependent (Schwindt et al., 1988; Schwindt et al., 1989; SanchezVives et al., 2000b). Because these intrinsic inhibitory mechanisms provide negative feedback in proportion to action

Received Jan. 15, 2013; revised June 18, 2013; accepted June 26, 2013.

Author contributions: A.T.G. designed research; A.T.G., S.D., K.O., E.K.S., J.M.H., and D.A. performed research; A.T.G., S.D., K.O., E.K.S., J.M.H., and D.A. analyzed data; A.T.G. wrote the paper.

This work was supported by a grant from the National Institutes of Health-National Institute for Mental Health (Grant \#R01 MH83806 to A.T.G.). We thank Ken Orndorff for assistance with microscopy, Rod Scott for assistance with statistical analyses, and Pierre-Pascal Lenck-Santini for providing the timings of the CA1 place cell spike train.

Correspondence should be addressed to Allan T. Gulledge, Department of Physiology and Neurobiology, Geisel School of Medicine at Dartmouth, One Medical Center Drive, DHMC, Borwell 718E, Lebanon, NH 03756. E-mail: allan.gulledge@dartmouth.edu.

DOI:10.1523/JNEUROSCI.0220-13.2013

Copyright $\odot 2013$ the authors $\quad 0270-6474 / 13 / 3313025-17 \$ 15.00 / 0$ potential output, they play a critical role in shaping the pattern of action potential generation in pyramidal neurons, and their dysregulation contributes to epilepsy (Behr et al., 2000; Empson and Jefferys, 2001) and age-related cognitive decline (Moyer et al., 1992).

In addition to potassium conductances, the sodiumpotassium ATPase (i.e., the "sodium pump") may provide a mechanism for intrinsic, activity-dependent regulation of excitability. The sodium pump contributes to ionic homeostasis via asymmetric exchange of three intracellular sodium ions for two extracellular potassium ions, thus generating a net outward current that may hyperpolarize cortical pyramidal neurons by several millivolts (Koike et al., 1972). Under physiological conditions, activity of the sodium pump is determined primarily by intracellular sodium concentration (Anderson et al., 2010), suggesting that sodium entry during trains of action potentials could produce hyperpolarizing pump currents contributing to the AHP (Koike et al., 1972). Indeed, sodium-pump-dependent AHPs have been described in Drosophila neurons (Pulver and Griffith, 2010), sensory neurons in the leech (Baylor and Nicholls, 1969) and lamprey (Parker et al., 1996), motor neurons in tadpoles (Zhang and Sillar, 2012), and in presynaptic and postsynaptic neurons at the calyx of Held in the mammalian medial nucleus of the trapezoid body (Kim et al., 2007; Kim and von Gersdorff, 2012). Further, a role for sodium pumps in generating AHPs has been suggested in CA1 pyramidal neurons (CA1PNs; Gustafsson and Wigström, 1981, 1983) and neocortical layer 5 pyramidal neurons (L5PNs; Koike et al., 1972). 

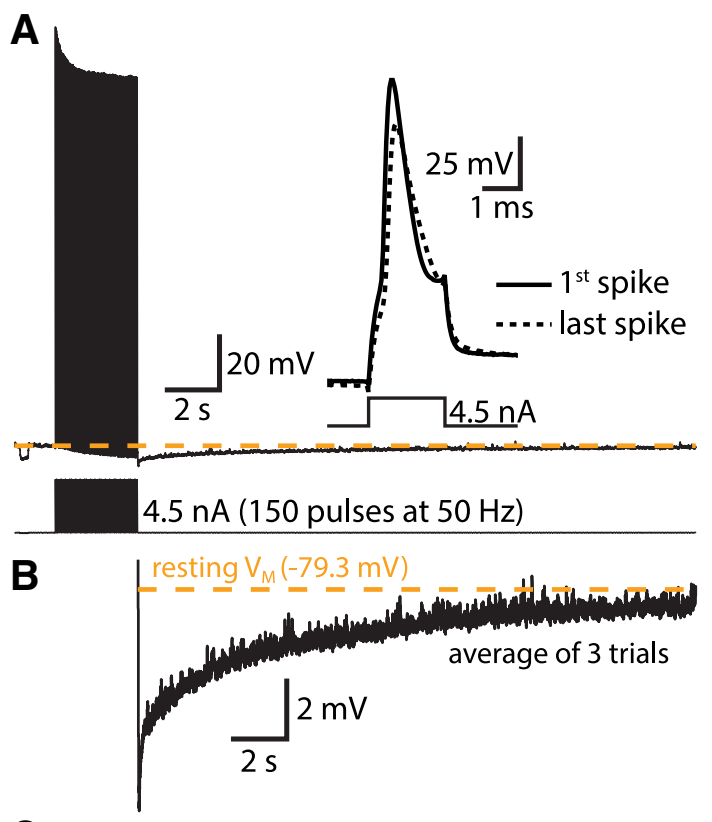

C

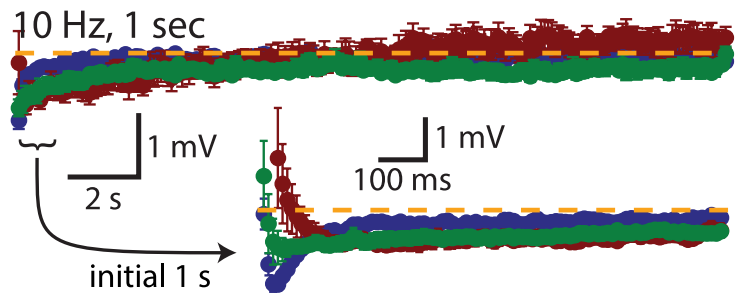

$25 \mathrm{~Hz}, 1 \mathrm{sec}$

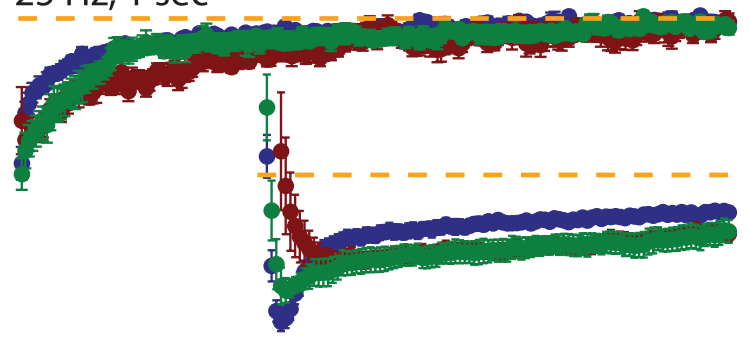

$50 \mathrm{~Hz}, 1 \mathrm{sec}$

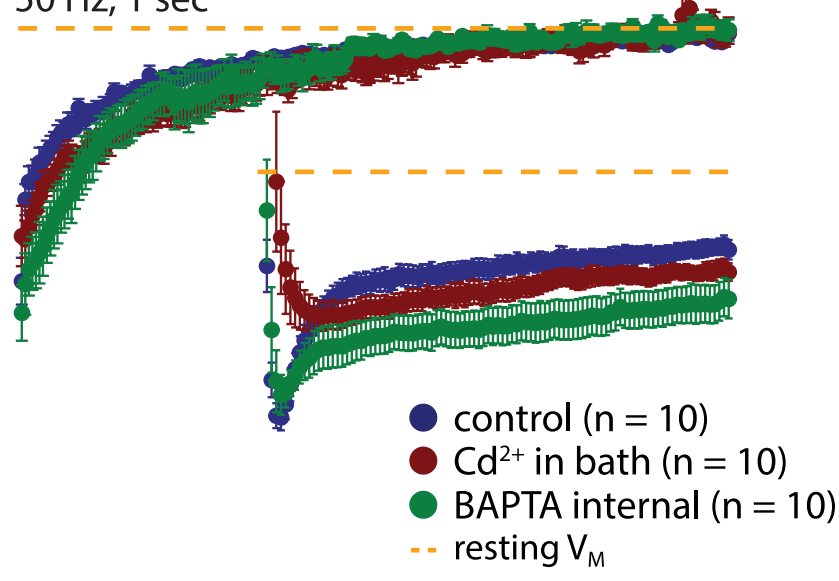

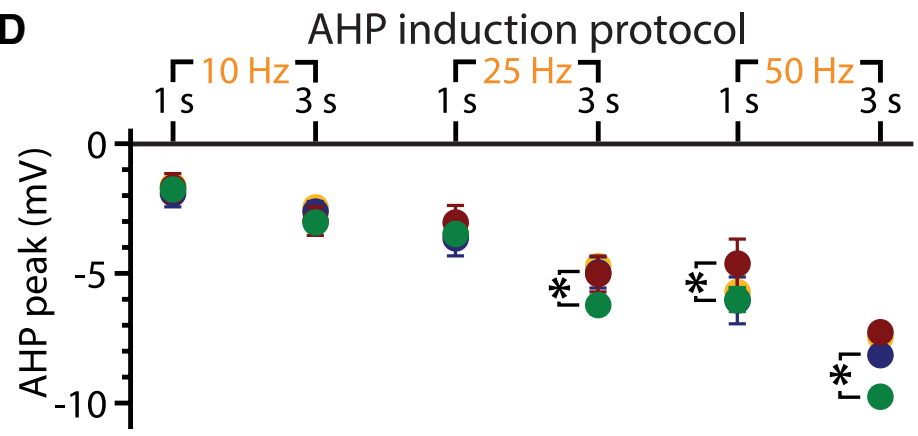

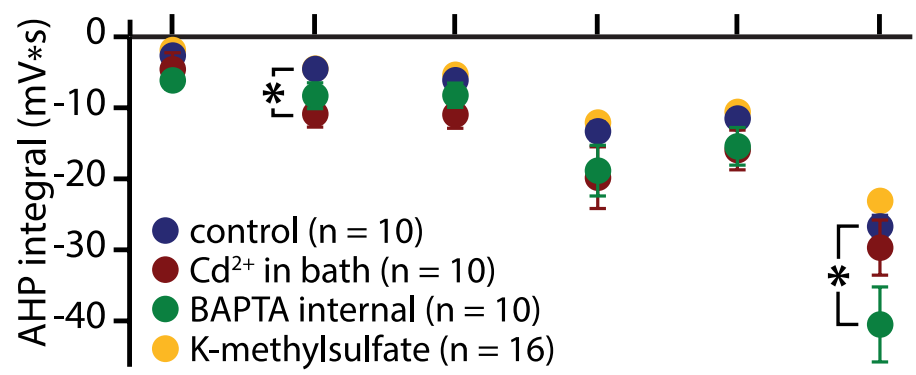

$10 \mathrm{~Hz}, 3 \mathrm{sec}$

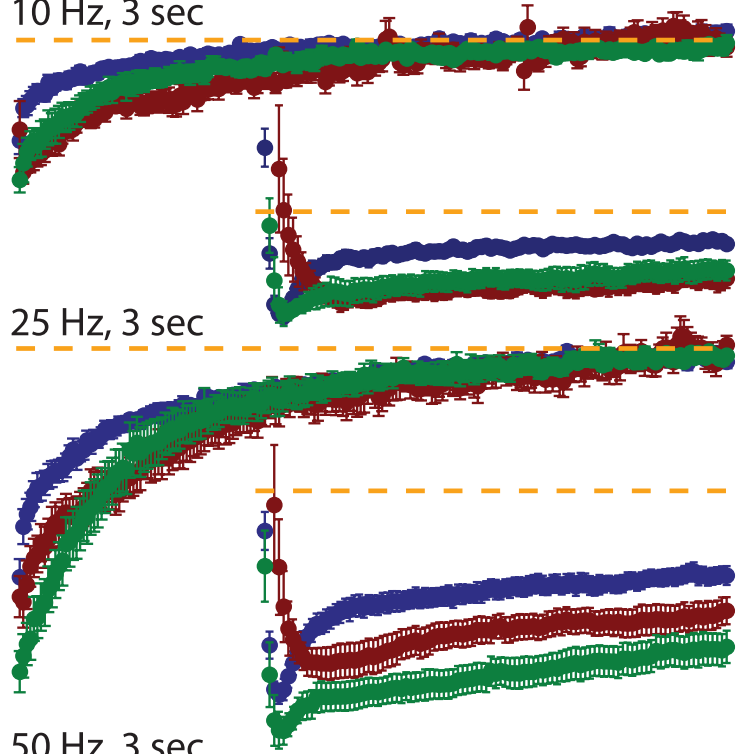

$50 \mathrm{~Hz}, 3 \mathrm{sec}$

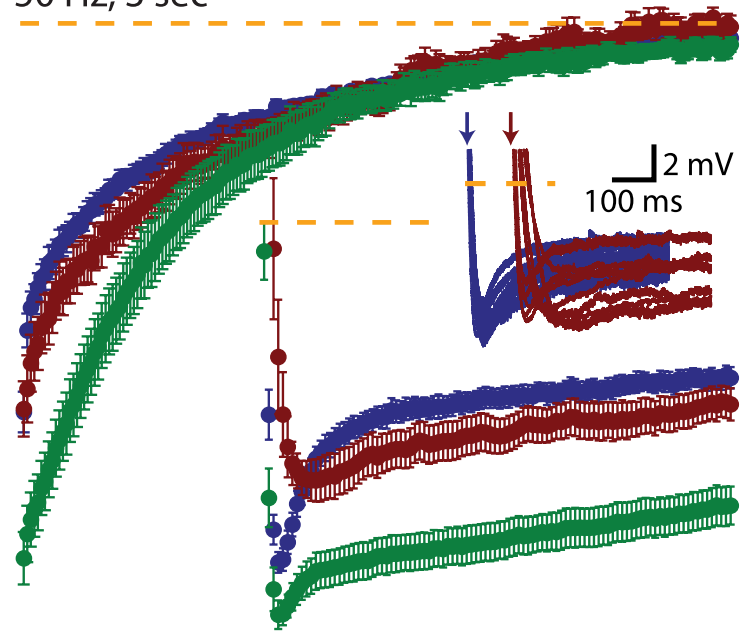

Figure 1. AHPs in L5PNs do not depend on intracellular calcium signaling. $A$, An AHP generated in a L5PN after a train of 150 action potentials ( $50 \mathrm{~Hz}, 3 \mathrm{~s})$. Dashed yellow line in this and other figures indicates the RMP, which in this neuron was $-82 \mathrm{mV}$. Inset: First (solid line) and final (dashed line) action potentials in the spike train. $\boldsymbol{B}$, Shown is the averaged AHP from the neuron in $\boldsymbol{A}$ (three consecutive trials). C, "Population AHPs" (averaged AHPs from each neuron resampled at $10 \mathrm{~Hz}$, then plotted as population mean \pm SEM for each resulting time point) (Figure legend continues.) 
In a recent study, we observed long-lasting ( $\sim 20 \mathrm{~s})$ AHPs after trains of action potentials in hippocampal CA1PNs (Dasari and Gulledge, 2011). Here, we test the mechanisms underlying these prolonged AHPs in both L5PNs and CA1PNs. Our results demonstrate a robust role for the sodium pump in regulating pyramidal neuron excitability that can be engaged by brief, physiologically relevant spike trains that occur in vivo. Because electrogenic sodium pumps are expressed in all cells, we propose that they represent a fundamental mechanism for regulating excitability in most, if not all, neurons.

\section{Materials and Methods}

Slice preparation. Experiments were performed using wild-type C57BL/6 mice of either sex under procedures approved by the Institutional Animal Care and Use Committee of Dartmouth College. Animals (4- to 6-weeks-old, unless otherwise indicated) were briefly anesthetized with isoflurane, decapitated, and brains rapidly removed into artificial CSF (aCSF) composed of the following (in $\mathrm{mm}$ ): $125 \mathrm{NaCl}, 25 \mathrm{NaHCO}_{3}, 3$ $\mathrm{KCl}, 1.25 \mathrm{NaH}_{2} \mathrm{PO}_{4}, 0.5 \mathrm{CaCl}_{2}, 6 \mathrm{MgCl}_{2}$, and 25 glucose (saturated with $\left.95 \% \mathrm{O}_{2} / 5 \% \mathrm{CO}_{2}\right)$. Coronal brain slices $(250 \mu \mathrm{m}$ thick) of the medial prefrontal cortex (mPFC) or dorsal hippocampus were cut using a Leica VT 1200 slicer, and transferred to a storage chamber filled with aCSF in which $\mathrm{CaCl}_{2}$ was increased to $2 \mathrm{~mm}$ and $\mathrm{MgCl}_{2}$ was decreased to $1 \mathrm{~mm}$. Slices were maintained at $35^{\circ} \mathrm{C}$ for $1 \mathrm{~h}$, and then stored at room temperature $\left(23^{\circ} \mathrm{C}\right)$ before experimental manipulation.

Electrophysiology. Slices were placed in a recording chamber and continuously perfused $(\sim 5 \mathrm{ml} / \mathrm{min})$ with aCSF heated to $35^{\circ} \mathrm{C}$, unless otherwise indicated. Whole-cell current-clamp recordings were made under visual control from L5PNs in the mPFC, or from CA1PNs in the hippocampus, using $60 \times$ water-immersion objectives and differential interference contrast optics on BX51WI microscopes (Olympus) equipped with MP-285 micromanipulators (Sutter Instruments). Except as indicated, pipette solutions contained the following (in mM): $135 \mathrm{~K}$-gluconate, 2 $\mathrm{NaCl}, 2 \mathrm{MgCl}_{2}, 10$ HEPES, $3 \mathrm{Na}_{2} \mathrm{ATP}$, and $0.3 \mathrm{NaGTP}$, pH 7.2 with $\mathrm{KOH}$. Most electrophysiological recordings were made with BVC-700 amplifiers (Dagan). During ion imaging experiments, we used a MultiClamp 700B amplifier (Molecular Devices). Data were acquired and analyzed using AxoGraph software (AxoGraphX). Voltage signals were sampled at $22-40 \mathrm{kHz}$, filtered at $5 \mathrm{kHz}$, and corrected for the liquid junction potential ( $+12 \mathrm{mV}$ for K-gluconate-based intracellular saline and $+8 \mathrm{mV}$ for K-methylsulfate-based saline). Except as noted, action potentials were evoked using brief ( $2 \mathrm{~ms}$ ), high-amplitude (3-4.5 nA) current injections, allowing precise control of the number and timing of action potentials within spike trains. The "place cell train" (PCT) replicated the timings of a burst of activity ( 15 action potentials over a $345 \mathrm{~ms}$ period) recorded in vivo in a CA1PN of a rat traversing the associated place field (kindly provided by Dr. Pepe Lenck-Santini). Voltage responses were baselined to the resting membrane potential (RMP) occurring just before initiation of the spike train (averaged over $150 \mathrm{~ms}$ just before the first current step) and AHP peak amplitudes were measured as the peak negative voltage after the cessation of the final current step in the unresampled raw data. AHP integrals were determined from the AHP

\section{$\leftarrow$}

(Figure legend continued.) for control neurons (blue; $n=10$ ) and neurons recorded in the presence of external $\mathrm{Cd}^{2+}(200 \mu \mathrm{m}$; red; $n=10)$ or internal BAPTA (10 mm; green; $\left.n=10\right)$. Inset: Initial $1 \mathrm{~s}$ of the population AHP resampled at $100 \mathrm{~Hz}$. Mean RMPs were $-81 \pm 1 \mathrm{mV}$ for control neurons, $-82 \pm 1 \mathrm{mV}$ in the presence of $\mathrm{Cd}^{2+}$, and $-78 \pm 1 \mathrm{mV}$ in BAPTA-filled neurons. $\boldsymbol{D}$, Comparisons of AHP peak amplitudes (top) and integrals (bottom) for the various spike train protocols and recording conditions shown in $C$, as well as for experiments in which whole-cell pipettes were filled with a K-methylsulfate-based intracellular solution $(n=16$; mean RMP for KMS-filled neurons was $-79 \pm 1 \mathrm{mV}$ ). Significant differences relative to control neurons are indicated $\left({ }^{*} p<0.05\right.$, one-way ANOVAs). Note that the apparent smaller peak amplitude of population AHPs occurring in the presence of $\mathrm{Cd}^{2+}$ (see inset of individual $50 \mathrm{~Hz}$, $3 \mathrm{~s}$ responses in C) reflects instead increased variability in the time-to-peak (SD of latency to peak was $10 \pm 1 \mathrm{~ms}$ in control neurons vs $149 \pm 31 \mathrm{~ms}$ for neurons patched in the presence of $\left.\mathrm{Cd}^{2+} ; n=30 ; p<0.01, \mathrm{ANOVA}\right)$, rather than an absolute change in AHP peak amplitude (D). waveform (baselined to $0 \mathrm{mV}$ at the RMP and with time 0 set at the end of the last current step) by measuring the maximum negative amplitude of the voltage integral between time 0 and $20 \mathrm{~s}$. "Population AHPs" were generated by resampling individual AHPs (averaged from 3 consecutive trials) at $10 \mathrm{~Hz}$ (or $100 \mathrm{~Hz}$ for the initial $1 \mathrm{~s}$ ) and then plotting the population mean $( \pm \mathrm{SEM})$ for each resultant time point. During ion-imaging experiments, series resistance compensation during highamplitude current injections was imperfect. Therefore, to most accurately compare action potential amplitudes in baseline and drug conditions, voltage traces were baselined to the minimum voltage occurring between the fast capacitive transient (at the start of the first current step) and the peak of the first action potential (Fig. 3A). All action potential amplitudes in a given train were measured relative to this same baseline potential.

Ion-imaging experiments. For ion-imaging experiments, patch-pipette solutions included either the calcium-sensitive dye Oregon Green BAPTA-1 (OGB1; $50 \mu \mathrm{M}$ ) or the sodium-sensitive dye SBFI (1 mM), both obtained from Life Technologies. Dye-loaded neurons were visualized using 2-photon excitation via a Prairie Ultima imaging system equipped with a Ti:sapphire laser (Coherent) tuned to $820 \mu \mathrm{m}$ for both OGB1 and SBFI imaging. Regions of interest were positioned over the soma of the recorded neuron to allow relatively fast $(\sim 20 \mathrm{~Hz})$ sampling of somatic fluorescence (presented as $\Delta F / F$ ). The decay of fluorescence signals were fit with single exponentials. The corresponding AHPs were fit with double-exponential functions.

Pharmacological manipulations. Drugs were obtained from SigmaAldrich. Tetrodotoxin (TTX; $1 \mu \mathrm{M})$ and ouabain $(20 \mu \mathrm{M})$ were dissolved in aCSF and focally applied via patch-pipettes positioned near the soma of the recorded neuron. Cadmium chloride $(200 \mu \mathrm{M})$ and cesium chloride $(3 \mathrm{~mm})$ were bath applied. In nominally $\mathrm{K}^{+}$-free aCSF, $\mathrm{KCl}$ was replaced with $\mathrm{NaCl}$.

Statistical analysis. Drug effects were assessed using either Student's $t$ test (two-tailed, paired or unpaired) or one-way ANOVAs (two-tailed, for independent or repeated-measures) with Tukey-Kramer post tests, as appropriate. The effects of the PCT on test-pulse spike latency were quantified using generalized linear modeling for repeated measures with SPSS Statistics version 19.0.0 software. $p$ values $<0.05$ were considered significant.

\section{Results}

\section{Sodium-dependent AHPs in L5PNs}

We used brief (2 ms), high-amplitude (3-4.5 nA) somatic current injections to initiate time-locked action potential trains of varying frequency and duration $(10-50 \mathrm{~Hz}, 1$ or $3 \mathrm{~s})$ in L5PNs from the $\mathrm{mPFC}$. These action potential trains generated prolonged ( $20 \mathrm{~s}$ ) AHPs (Fig. $1 A-C)$, the amplitudes and integrals of which increased with the number of action potentials in the spike train $(n=10$; Fig. $1 D)$. AHPs in many cell types, including cortical neurons, are calcium dependent (for review, see Andrade et al., 2012). We investigated whether AHPs in L5PNs depend upon calcium entry through voltage-gated calcium channels and/or intracellular calcium signaling using two approaches that block calcium-dependent responses in cortical neurons (Gulledge et al., 2007; Dasari et al., 2013). In one set of experiments, we measured AHPs generated in the presence of the nonselective calcium channel blocker cadmium $(200 \mu \mathrm{M} ; n=$ $10)$, whereas in another set of experiments, we measured AHPs in L5PNs in which the calcium-chelating agent BAPTA (10 mM) was included in the patch-pipette $(n=10)$. AHPs generated in both conditions were generally as large (in terms of peak amplitude and integral) or larger than AHPs generated in control conditions (Fig. 1C,D). For the largest AHPs, generated by $50 \mathrm{~Hz}, 3$ s trains of action potentials, AHP peak amplitudes were $8.1 \pm 0.3 \mathrm{mV}, 7.3 \pm$ $0.3 \mathrm{mV}$, and $9.8 \pm 0.3 \mathrm{mV}$ for control, cadmium, and BAPTA conditions, respectively $(n=10$ per group; $p<0.01$ for cells filled with BAPTA vs control and cadmium experiments, ANOVA). AHP 
B
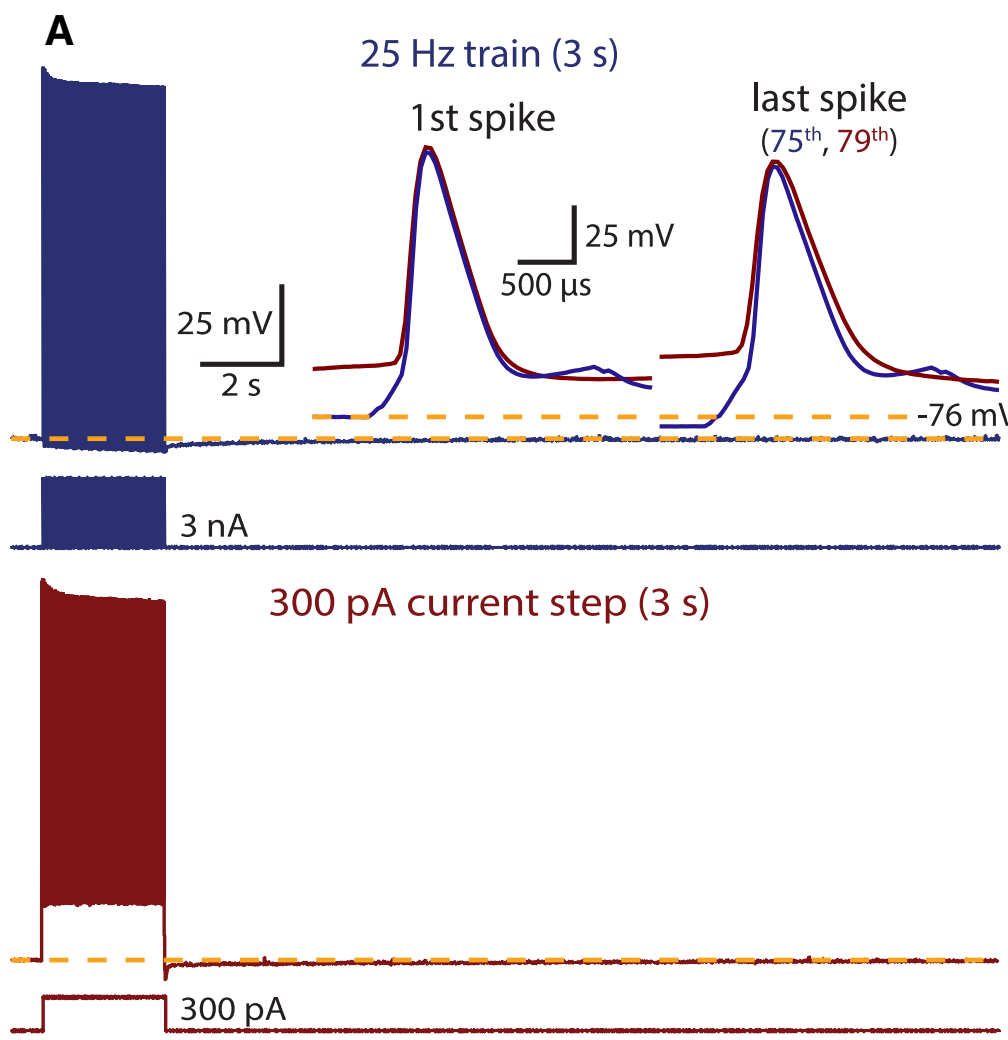

$25 \mathrm{~Hz}, 3$ s (75 spikes / trial)

$300 \mathrm{pA}, 3 \mathrm{~s}$ (average of 79.33 spikes / trial)
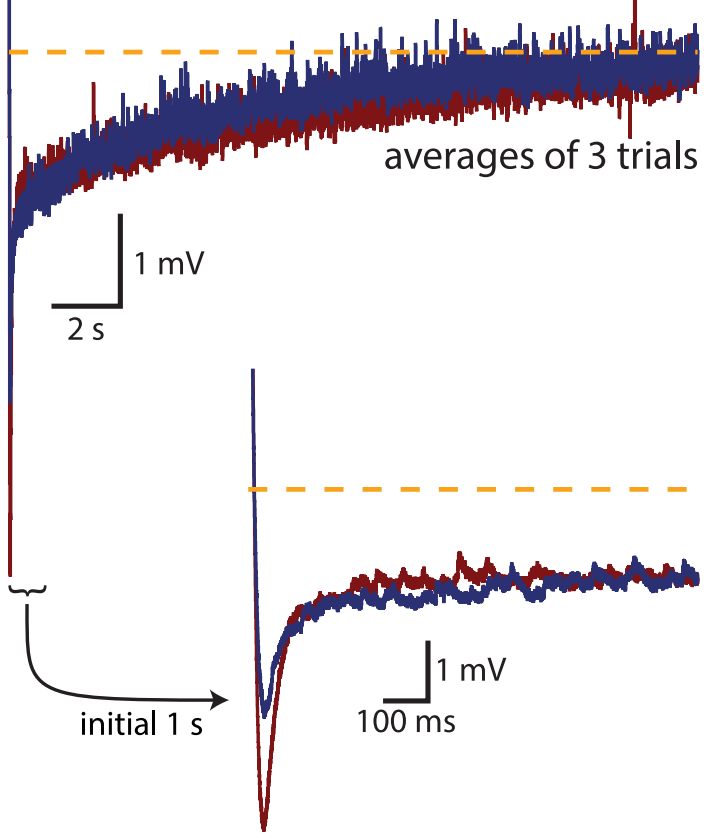

C

\section{Control conditions}

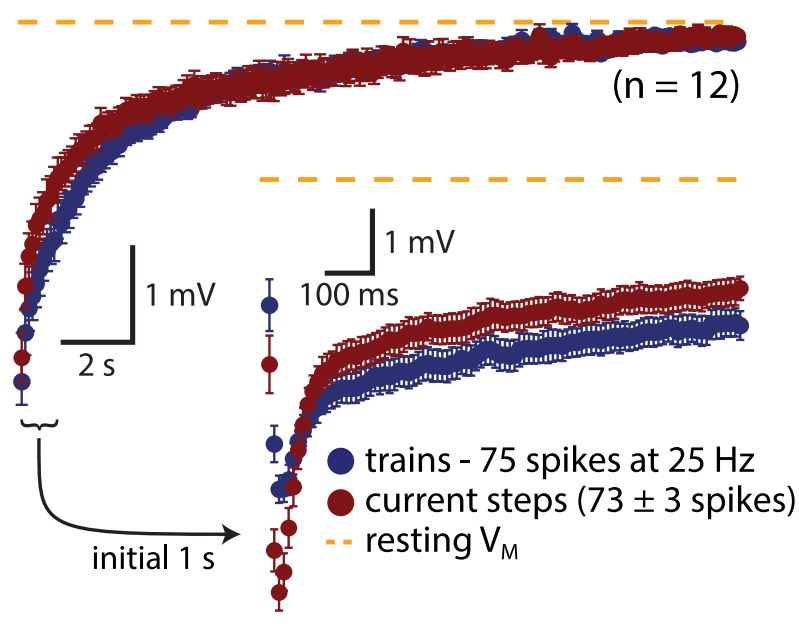

D

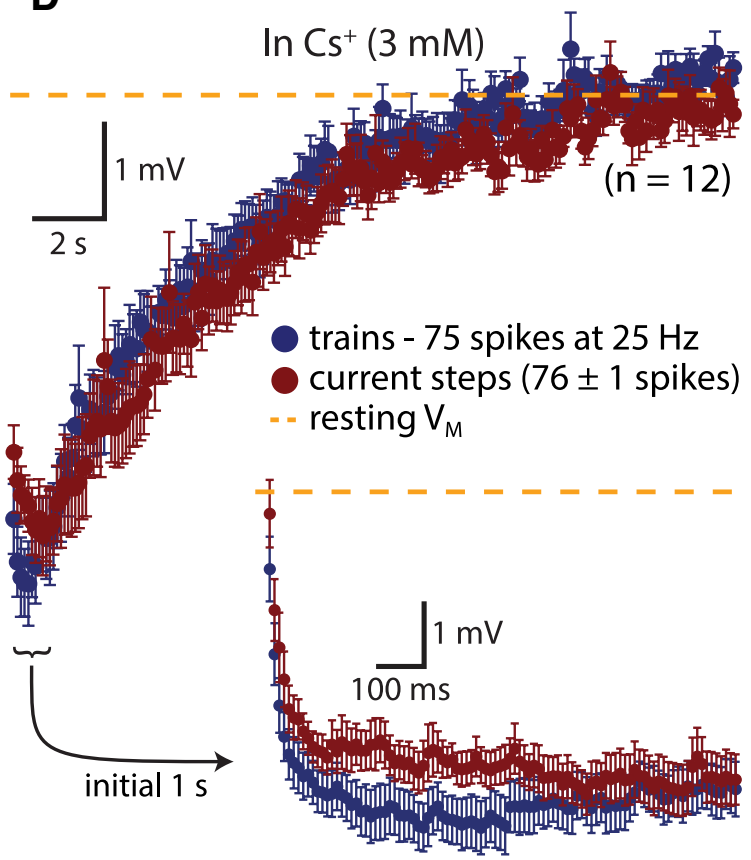

Figure 2. The slow component of the AHP is independent of AHP induction protocol. A, AHPs generated in the same neuron by trains of high-amplitude current $\mathrm{steps}(25 \mathrm{~Hz}, 3 \mathrm{~s}$; top, blue trace) or by a single $3 \mathrm{~s}$, low-amplitude, current step (bottom, red trace). Inset are the first (left) and last (right) action potentials in each train superimposed to show the similarities in action potential waveforms. The RMP of this neuron (yellow dashed line) was $-76 \mathrm{mV}$. $\boldsymbol{B}$, Superimposed AHPs from the neuron shown in $\boldsymbol{A}$ (averages of three consecutive trials) generated by timed trains of action potentials $(25 \mathrm{~Hz}, 3 \mathrm{~s}$; blue), or by a $3 \mathrm{~s}, 300 \mathrm{pA}$ current step (red). Note that the AHPs are similar except for the initial $100 \mathrm{~ms}$, which is larger in the case where a long current step was used to generate the AHP. C, Population AHPs (resampled at 10 Hz; $n=12$ ) generated by timed action potential trains (blue) or 3-s-long current steps (red). Inset: Initial 1 s of the AHP resampled at $100 \mathrm{~Hz}$. The mean RMP for these neurons was $-76 \pm 2 \mathrm{mV}$. D, Population AHPs $(n=12)$ generated by timed action potential trains (blue) or by 3-s-long current steps (red) in the presence of the HCN channel blocker $\mathrm{Cs}^{+}(3 \mathrm{~mm})$. Inset is the initial $1 \mathrm{~s}$ of the AHP resampled at $100 \mathrm{~Hz}$. Mean RMP of these neurons was $-79 \pm 1 \mathrm{mV}$. 

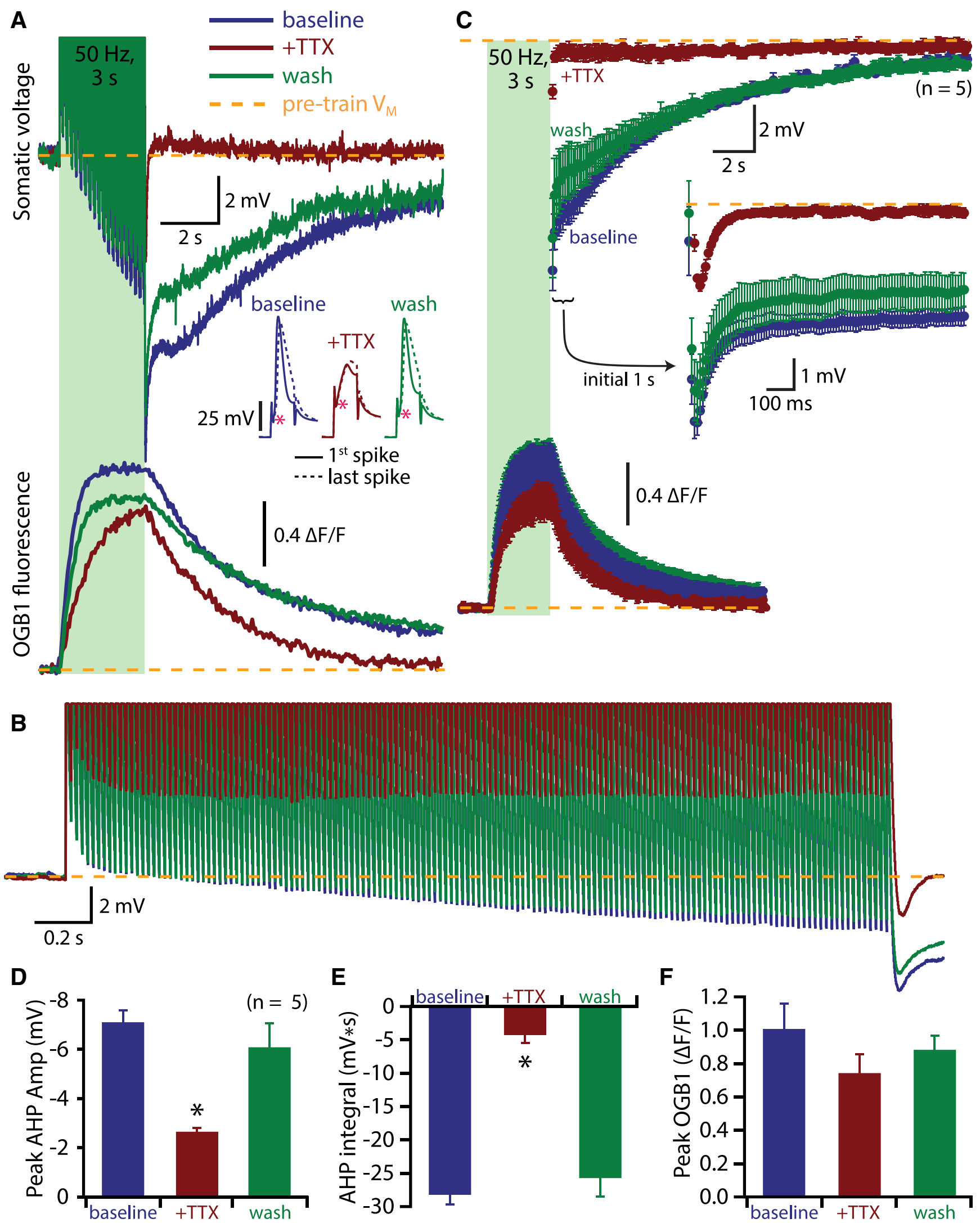

Figure 3. AHPs in L5PNs are TTX-sensitive. $A$, Recordings of membrane potential (top) and changes in intracellular calcium as reflected by changes in 0GB1 fluorescence (bottom; reported as $\Delta F / F$ ) from an L5PN experiencing $50 \mathrm{~Hz}, 3$ s trains of action potentials in baseline conditions (blue), after focal application of $1 \mu \mathrm{m} \mathrm{TTX} \mathrm{(red),} \mathrm{and} \mathrm{after} \mathrm{several} \mathrm{minutes} \mathrm{of} \mathrm{wash} \mathrm{(green).} \mathrm{The} \mathrm{presence}$ of TTX largely blocks all but the initial few hundred milliseconds of the AHP. Inset: Close-ups of the first and last action potentials occurring in each experimental condition demonstrating the effective block of action potential generation by TTX. Pink asterisks mark the baseline voltage from which action potential amplitudes were determined (see Materials and Methods). The RMP of this neuron was $-78 \mathrm{mV}$ in baseline conditions, and $-77 \mathrm{mV}$ during both focal TTX application and wash. $\boldsymbol{B}$, Lower portion of the spike train in $\boldsymbol{A}$ at higher temporal resolution showing that TTX blocks the progressive hyperpolarization during the spike train that occurs during baseline and wash conditions. C, Population AHPs (top) and population changes in OGB1 fluorescence (Figure legend continues.) 
integrals were $27 \pm 2 \mathrm{mV} \cdot \mathrm{s}, 30 \pm 4 \mathrm{mV} \cdot \mathrm{s}$, and $40 \pm 5 \mathrm{mV} \cdot \mathrm{s}(p<0.05$ for BAPTAfilled neurons vs controls). Finally, we compared our control AHPs, recorded with standard K-gluconate-based pipette saline, with AHPs generated in L5PNs patched with pipettes containing a K-methylsulfate-based pipette solution ( $n=16$; Fig. $1 D$, yellow symbols). We found no significant differences in the amplitudes or integrals of AHPs generated in these two recording conditions, suggesting that, under our conditions, AHPs are not dependent on intracellular anion species (but see Zhang et al., 1994). These results demonstrate that calcium entry during spike trains is not required for AHPs to occur in L5PNs.

We next compared AHPs generated by trains of timed action potentials (Fig. 1) with AHPs resulting from equivalent numbers of action potentials generated by prolonged low-amplitude current injections (Fig. 2). In 12 L5PNs, AHPs were evoked by 75 high-amplitude current injections $(25 \mathrm{~Hz})$ or by a 3-s-long lowamplitude current step $(320 \pm 31 \mathrm{pA})$ that produced a mean of $73 \pm 3$ action potentials (Fig. 2A). Action potential waveforms were similar in both AHP induction protocols (Fig. 2A), and the resulting AHPs had similar integrals $(13 \pm 1 \mathrm{mV} \cdot \mathrm{s}$ for trains vs $12 \pm 2 \mathrm{mV} \cdot \mathrm{s}$ for long current steps; $n=12 ; p=0.61$ ). However, AHPs in response to long current injections had peak amplitudes $(6.5 \pm 0.3 \mathrm{mV})$ that were $31 \pm 5 \%$ larger than AHPs generated by timed spike trains $(5.0 \pm 0.2 \mathrm{mV} ; p<$ 0.0001 , paired $t$ test; Fig. $2 B, C)$. The increase in AHP amplitude was brief, lasting only $131 \pm 41 \mathrm{~ms}$ (Fig. $2 \mathrm{~B}, \mathrm{C}$ ), corresponding to the medium AHP that in pyramidal neurons at RMPs is mediated by inactivation of hyperpolarization- and cAMP-gated nonspecific cation (HCN) channels (Gu et al., 2005). To confirm that HCN channel inactivation during long current steps was responsible for the observed difference in AHP peak amplitudes, in a second set of experiments, we blocked HCN channels with $3 \mathrm{~mm}$ cesium chloride (Chen et al., 2005). In the presence of $\mathrm{Cs}^{+}$, AHPs generated by the two induction protocols were almost identical (Fig. $2 D$ ), with AHP peak amplitudes being $5.8 \pm 0.4$ and $5.4 \pm 0.3$ $\mathrm{mV}$, for train-induced and long current step-induced AHPs, respectively $(p=0.26)$. These data demonstrate that the slow com-

(Figure legend continued.) (bottom) generated by resampling individual responses (at $10 \mathrm{~Hz}$ ) and displaying the mean \pm SEM for each time point. Inset: Initial $1 \mathrm{~s}$ of the AHP resampled at $100 \mathrm{~Hz}$. TTX (red traces) reduced the AHP relative to baseline (blue) and wash (green) conditions, while having only a modest effect on intracellular calcium accumulation. Mean RMPs were $-76 \pm 3 \mathrm{mV},-75 \pm 3 \mathrm{mV}$, and $-77 \pm 2 \mathrm{mV}$, respectively, for baseline, TTX, and wash conditions. $\boldsymbol{D}-\boldsymbol{F}$, Comparison of AHP peak amplitudes $(\boldsymbol{D})$, integrals $(\boldsymbol{E})$, and peak changes in OGB1 fluorescence $(\boldsymbol{F})$ in baseline conditions (blue), in the presence of TTX (red), and after wash (green; $n=5$ ). (ANOVAs).
B

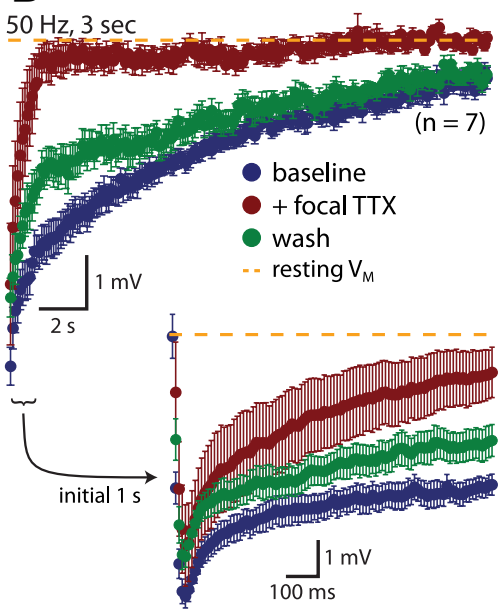

D
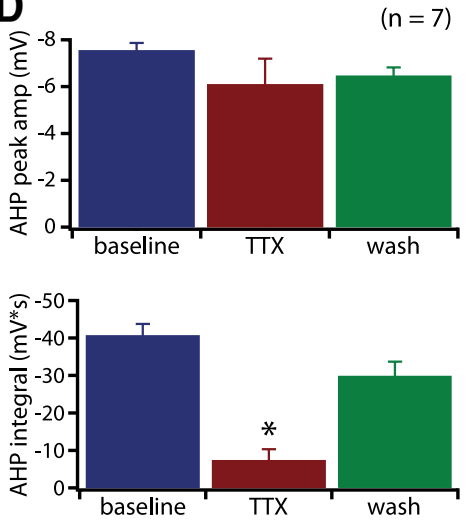

Figure 4. Sodium-dependent AHPs in hippocampal CA1PNs. $A$, Population AHPs generated by 150 action potentials $(50 \mathrm{~Hz})$ in CA1PNs recorded in control conditions (blue; $n=12$ ), in the presence of $200 \mu \mathrm{m}$ cadmium (red; $n=7$ ), or with $10 \mathrm{~mm}$ BAPTA included in the pipette solution (green; $n=15$ ). Mean RMPs were $-77 \pm 1 \mathrm{mV},-74 \pm 0 \mathrm{mV}$, and $-78 \pm 1 \mathrm{mV}$, for control, conditions (blue), after focal application of TTX (1 $\mu \mathrm{m}$; red), and after $10 \mathrm{~min}$ of wash (green). Mean RMPs were $-74 \pm 1 \mathrm{mV}$, $-75 \pm 1 \mathrm{mV}$, and $-74 \pm 1 \mathrm{mV}$, for baseline, TTX, and wash conditions, respectively. C, Comparisons of AHP peak amplitudes (top) and integrals (bottom) in control CA1PNs (blue), CA1PNs in the presence of $200 \mu \mathrm{M} \mathrm{Cd}^{2+}$ (red), and CA1PNs filled with $10 \mathrm{~mm}$ focal application of $1 \mu \mathrm{M} \mathrm{TTX} \mathrm{(red),} \mathrm{and} \mathrm{after} 15 \mathrm{~min}$ of wash (green). ${ }^{*} p<0.01$ compared with control or baseline conditions

ponent of the AHP is dependent primarily on the number of action potentials generated, rather than on the method of their induction. Because our focus is on understanding the mechanisms underlying the slow components of the AHP, and to have precise control of action potential number and timing, trains of brief, high-amplitude current pulses were used to generate AHPs in the experiments below.

Long-lasting, calcium-independent AHPs have been described previously in neocortical pyramidal neurons (Schwindt et al., 1988; Schwindt et al., 1989; Sanchez-Vives et al., 2000b). These AHPs rely instead on sodium entry during action potential trains, and are sensitive to the voltage-gated sodium channel blocker TTX. To determine whether sodium entry during spike trains mediates AHPs in L5PNs, we generated AHPs before and after focal application of TTX ( $1 \mu \mathrm{M}$; Fig. 3$)$. TTX reversibly reduced the amplitude of action potentials during the spike train (Fig. 3A), with initial action potentials being reduced by $63 \pm 6 \%$ and final spikes being reduced by $61 \pm 4 \%(n=5$; $p<0.001$ for each, relative to baseline spike amplitudes, paired $t$ tests). TTX also eliminated the progressive hyperpo- 

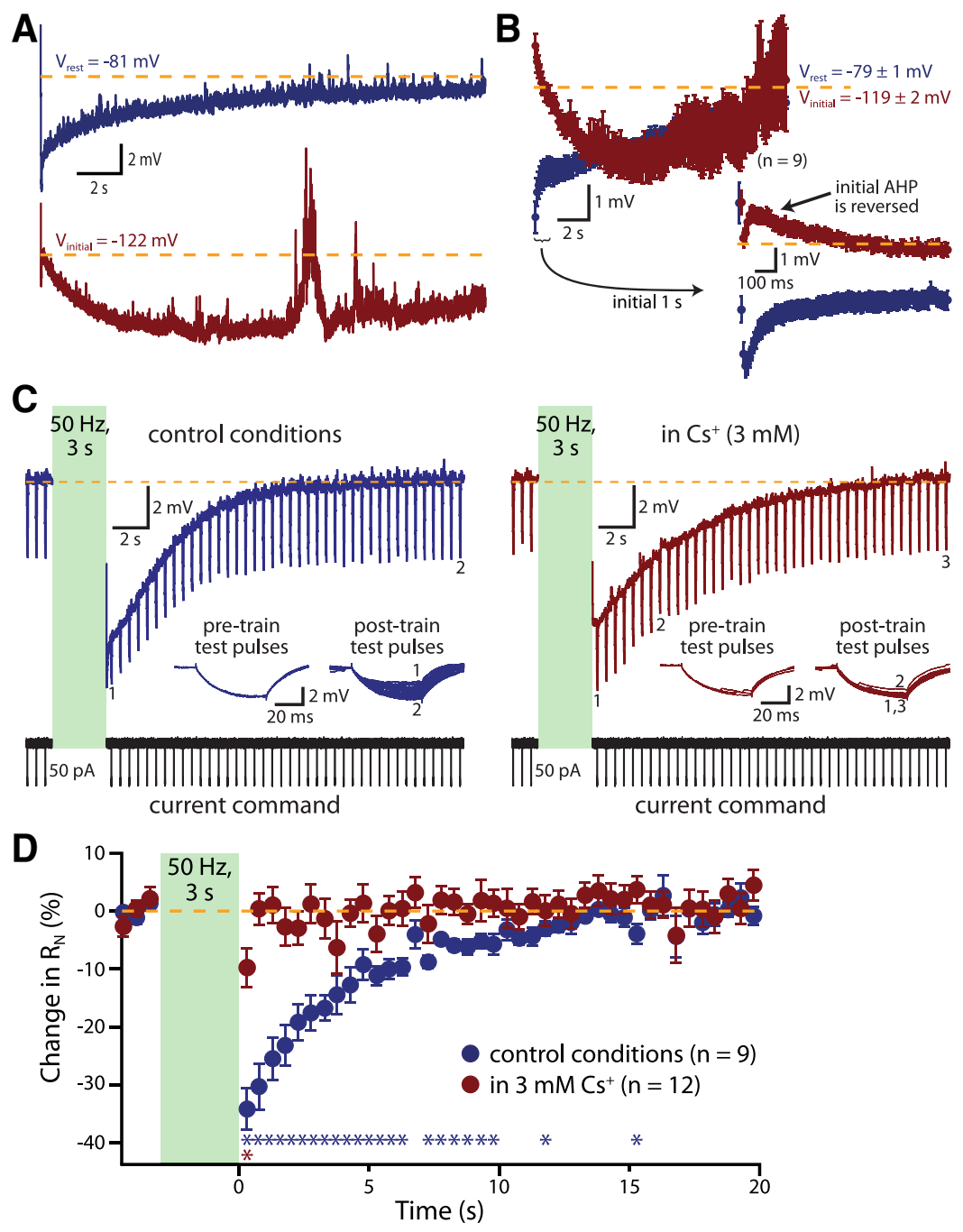

Figure 5. The slow component of the AHP is not due to an increase in potassium conductance. $A$, AHPs generated in a L5PN by $50 \mathrm{~Hz}, 3$ s trains of action potentials at the RMP ( $-81 \mathrm{mV}$; blue, top) and with the cell "held" at $-122 \mathrm{mV}$ using somatic $D C$ current injection (red, bottom). $\boldsymbol{B}$, Population AHPs (resampled at $10 \mathrm{~Hz} ; n=9$ ) obtained at RMPs (blue) and at hyperpolarized potentials (red). Inset: Initial $1 \mathrm{~s}$ of the AHPs resampled at $100 \mathrm{~Hz}$. C, AHPs in control conditions (left, blue trace) were associated with a decrease in $R_{N}$, as evidenced by decreased amplitude of voltage responses to current steps $(-50 \mathrm{pA})$ applied periodically $(2 \mathrm{~Hz})$ before and after the AHP-inducing spike train (inset, numbers indicate responses to first and last postspike train test pulses). Conversely, with $\mathrm{HCN}$ channels blocked with $3 \mathrm{~mm} \mathrm{Cs}{ }^{+}$(right, red trace), little change in $\mathrm{R}_{\mathrm{N}}$ was evident (compare variability of inset voltage responses occurring after AHP induction between control and $\mathrm{Cs}^{+}$conditions). The RMPs for the neurons in control and $\mathrm{Cs}^{+}$conditions were $-81 \mathrm{mV}$ and $-78 \mathrm{mV}$, respectively. $\boldsymbol{D}$, Plot of the change in $\mathrm{R}_{\mathrm{N}}$ (\% of baseline) occurring over time for AHPs generated in control conditions ( $n=9$; blue) or in the presence of $3 \mathrm{~mm} \mathrm{Cs}^{+}(n=12$; red). RMPs were $-78 \pm 1 \mathrm{mV}$ and $-79 \pm 1 \mathrm{mV}$ in control and $\mathrm{cs}^{+}$conditions, respectively. Asterisks (blue for control experiments, red for those in the presence of $\mathrm{Cs}^{+}$) indicate $p<0.05$ relative to baseline measurements.

larization that occurred during spike trains (Fig. 3B), reduced AHP peak amplitudes by $62 \pm 2 \%(p<0.05$, repeatedmeasures ANOVA; Fig. $3 A, C, D)$, and reduced AHP integrals by $84 \pm 5 \%(p<0.01$; Fig. $3 A, C, E)$. To ensure that blockade of sodium channels did not indirectly also block calcium entry, we simultaneously measured action-potential-induced calcium transients by monitoring OGB1 (100 $\mu \mathrm{M}$ in patchpipette) fluorescence (Fig. $3 A, C, F$ ). Compared with the robust reductions in AHP peak amplitude and integral in the presence of TTX, peak somatic calcium remained at $82 \pm 9 \%$ of baseline levels $(n=5 ; p=0.12)$, further suggesting that sodium, rather than calcium, serves as the primary activitydependent trigger for AHPs in cortical pyramidal neurons.
Sodium-dependent AHPs in CA1PNs Like L5PNs, CA1PNs in the hippocampus exhibit pronounced AHPs after spike trains (Dasari and Gulledge, 2011). We tested the roles of calcium and sodium in generating AHPs in CA1PNs in several ways. First, we compared AHPs generated by trains of action potentials in control neurons $(n=12)$ with AHPs generated in CA1PNs patched in the presence of cadmium (200 $\mu \mathrm{M} ; n=7)$ or with BAPTA (10 $\mathrm{mM})$ in the patch-pipette $(n=15)$. Trains of action potentials $(50 \mathrm{~Hz}, 3 \mathrm{~s})$ generated prolonged AHPs in all three groups (Fig. $4 A)$. Although AHP peak amplitudes (8.5 \pm 0.6 in control neurons) were slightly reduced in both cadmium ( $6.6 \pm$ $0.4 \mathrm{mV} ; p<0.05$, ANOVA) and BAPTA $(5.2 \pm 0.4 \mathrm{mV} ; p<0.01)$ conditions, no significant differences were observed in AHP integrals (Fig. 4C). Mean AHP integrals were $44 \pm 4 \mathrm{mV} \cdot \mathrm{s}, 42 \pm 2 \mathrm{mV} \cdot \mathrm{s}$, and $39 \pm 3 \mathrm{mV} \cdot \mathrm{s}$ for control, cadmiumexposed, and BAPTA-filled neurons, respectively $(p=0.61)$. Next, we measured AHPs before and after focal application of TTX ( $1 \mu \mathrm{M}$; Fig. $4 B, D$ ). TTX application reversibly reduced the amplitudes of the first and last action potentials by $65 \pm 3 \%$ and $56 \pm 6 \%$, respectively $(n=7 ; p<0.01$ for each, ANOVAs). TTX also reversibly reduced AHP integrals by $81 \pm 8 \%(n=7$; $p<0.01$, repeated-measures ANOVA), but did not significantly affect AHP peak amplitude (mean change in peak amplitude was $-20 \pm 14 \% ; p=0.2$ ). These results are consistent with L5PNs and CA1PNs sharing a common sodiumdependent mechanism that generates long-lasting AHPs after periods of activity, and suggest a calcium-mediated contribution to AHP peak amplitude in CA1PNs.

\section{The slow component of the AHP does not reflect a potassium conductance}

How might sodium entry during trains of action potentials contribute to the AHP? We hypothesized that activity-dependent increases in intracellular sodium activate sodium-dependent potassium channels to produce long-lasting outward currents that inhibit cortical pyramidal neurons (Schwindt et al., 1989; Sanchez-Vives et al., 2000b). We tested this hypothesis in several ways. First, we attempted to "reverse" the AHP by hyperpolarizing neurons below the equilibrium potential for potassium ( $-100 \mathrm{mV}$ in our experimental conditions). If AHPs are mediated by a potassium conductance, holding neurons below the potassium equilibrium potential should lead to prolonged depolarizing, rather than hyperpolarizing, afterpotentials following spike trains. However, spike trains $(50 \mathrm{~Hz}, 3 \mathrm{~s})$ in L5PNs $(n=9)$ generated similar hyperpolarizing AHPs at resting potentials (mean RMP of $-79 \pm 1 \mathrm{mV}$ ) and at very hyperpolarized potentials 
$(-119 \pm 2 \mathrm{mV})$ achieved via somatic current injection (Fig. 5A,B). Only the initial few hundred milliseconds of the AHP "reversed" (mean duration of reversed portion of the AHP was $694 \pm 206 \mathrm{~ms} ; n=9$ ), with the bulk of the AHP continuing to hyperpolarize neurons at very negative membrane potentials.

In a second test for a potassium conductance, we monitored whole-cell input resistance $\left(R_{N}\right)$ over time with brief $(50$ $\mathrm{ms})$ hyperpolarizing current pulses $(-50$ pA) delivered at $500 \mathrm{~ms}$ intervals (Fig. $5 C)$. Spike trains $(50 \mathrm{~Hz}, 3 \mathrm{~s})$ produced an initial decrease in $\mathrm{R}_{\mathrm{N}}$ of $34 \pm 4 \%(n=9$; $p<0.0001$ ), which decayed exponentially with a time constant of $4.8 \pm 0.7 \mathrm{~s}$. However, $R_{N}$ is itself voltage dependent in pyramidal neurons, due primarily to $\mathrm{HCN}$ channel expression in dendrites (Surges et al., 2004). To determine the contribution of HCN channels to AHP-associated reductions in $\mathrm{R}_{\mathrm{N}}$, we conducted a second set of experiments in the presence of $3 \mathrm{~mm}$ cesium chloride (Fig. 5C). In the presence of $\mathrm{Cs}^{+}$, baseline $\mathrm{R}_{\mathrm{N}}$ was mostly unaffected by the AHP, with a significant change from baseline $\mathrm{R}_{\mathrm{N}}(-10 \pm 3 \%)$ occurring only during the initial post-train test pulse (Fig. $5 D ; p<0.01$ ), even though mean AHP peak amplitudes in the presence of $\mathrm{Cs}^{+}(8.7 \pm 0.4 \mathrm{mV})$ were similar to those in control conditions $(8.5 \pm 0.5 \mathrm{mV} ; n=$ 9; $p=0.72$ ) and AHP integrals were nearly twice as large as in control conditions $\left(60 \pm 5 \mathrm{mV} \cdot \mathrm{s}\right.$ with $\mathrm{Cs}^{+}$present, $31 \pm 2 \mathrm{mV} \cdot \mathrm{s}$ in control conditions, $p<$ 0.0001; compare also Fig. 2C,D). These results indicate that reductions in $\mathrm{R}_{\mathrm{N}}$ after spike trains depend mostly on voltage-dependent activation of HCN channels, rather than on mechanisms underlying the AHP.

Finally, in a third test for potassium conductances, we measured AHPs in L5PNs and CA1PNs before and after removal of extracellular potassium (Fig. 6; Wang and Huang, 2006). Removal of extracellular potassium increased the amplitude of the initial portion $(\sim 1 s)$ of the AHP, but reversibly blocked (in L5PNs; $n=9$; Fig. $6 A$ ), or had no effect on (in CA1PNs; $n=9$; Fig. $6 B$ ), the bulk of the AHP. In L5PNs, removal of extracellular potassium reversibly increased AHP peak amplitudes from $7.7 \pm$ $0.3 \mathrm{mV}$ to $12.1 \pm 1.5 \mathrm{mV}(p<0.05$, repeated-measures ANOVA), but reduced AHP integrals from $29 \pm 2 \mathrm{mV} \cdot \mathrm{s}$ to $15 \pm$ $5 \mathrm{mV} \cdot \mathrm{s}(p<0.05$; Fig. $6 C)$. In CA1PNs, removal of extracellular potassium reversibly enhanced AHP peak amplitudes from $7.3 \pm$ $0.3 \mathrm{mV}$ to $13.3 \pm 1.0 \mathrm{mV}(p<0.01)$, but did not significantly change AHP integrals ( $p=0.73$; Fig. $6 D)$.

Why the differential effect of potassium removal on AHP integrals in L5PNs and CA1PNs? It is possible that potassium efflux during prolonged spike trains is not cleared rapidly enough in tightly packed CA1PNs to sufficiently reduce extracellular potassium to levels needed to block the AHP (see also Fig. 12, bottom, where removal of extracellular potassium blocks AHPs generated by a briefer spike train in CA1PNs). However, even with this
L5PN

$50 \mathrm{~Hz}, 3 \mathrm{sec})$
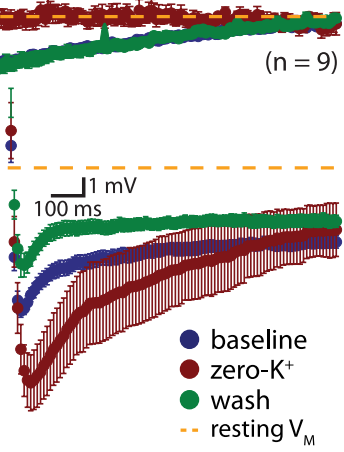

$(n=9)$
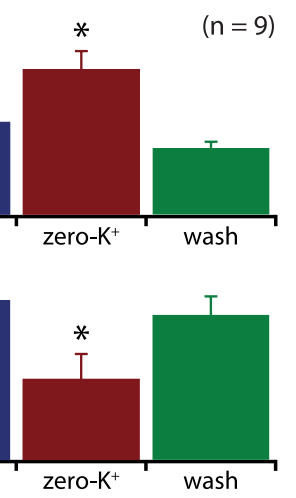

B

CA1

(50 Hz, $3 \mathrm{sec})$
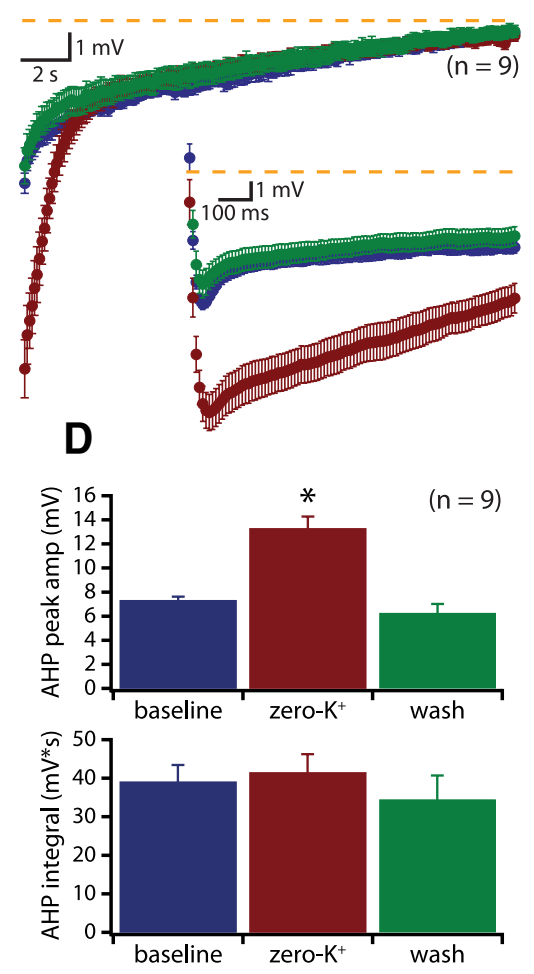

Figure 6. Removing extracellular potassium reduces, rather than increases, the slow component of the AHP. $A, B$, Population AHPs (resampled at $10 \mathrm{~Hz}$; mean \pm SEM) for L5PNs $(\boldsymbol{A})$ and CA1PNs $(\boldsymbol{B})$ in response to $50 \mathrm{~Hz}, 3$ s trains of action potentials under (blue), after $\sim 10 \mathrm{~min}$ of exposure to potassium-free aCSF (red), and after $5 \mathrm{~min}$ of wash with regular aCSF 列 the AHP in CA1PNs. ${ }^{*} p<0.01$ compared with baseline (repeated-measures ANOVA)

differential effect in L5PNs and CA1PNs, the failure of potassium removal to enhance the slow portion of the AHP in both neuron types, and the reversible block of the slow portion of the AHP in L5PNs, suggest that increased potassium conductance contributes only to the initial $\sim 1$ s of the AHP.

AHP is primarily mediated by the sodium-potassium ATPase If potassium conductances are not primarily responsible for AHPs, what other mechanisms might be? Our finding that removal of extracellular potassium can block, rather than increase, the AHP suggests a role for the sodium-potassium ATPase (i.e., the "sodium pump"), which requires extracellular potassium for its function. Because the sodium pump exchanges three cytosolic sodium ions for two extracellular potassium ions, it is intrinsically electrogenic and generates hyperpolarizing current when activated. We tested the role of the sodium pump in L5PNs and CA1PNs by generating AHPs ( $50 \mathrm{~Hz}, 3 \mathrm{~s}$ spike trains) before and after focal application of the sodium pump inhibitor ouabain $(20 \mu \mathrm{M} ; 2$ min duration; Fig. 7). At $20 \mu \mathrm{M}$, ouabain had little, if any, effect on RMP. Mean changes in RMP after ouabain application were $1.6 \pm$ $0.3 \mathrm{mV}(p<0.05$, paired $t$ test $)$ and $0.0 \pm 2.1 \mathrm{mV}(p=0.98)$ for L5PNs $(n=10)$ and CA1PNs $(n=8)$, respectively (Desfrere et al., 2009). However, ouabain significantly inhibited AHPs in both L5 (Fig. 7A) and CA1 (Fig. 7B) pyramidal neu- 
A
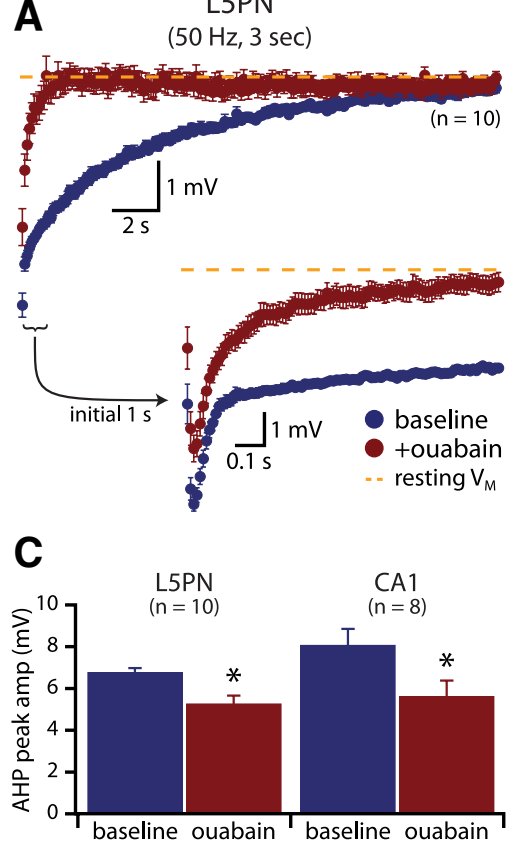

B
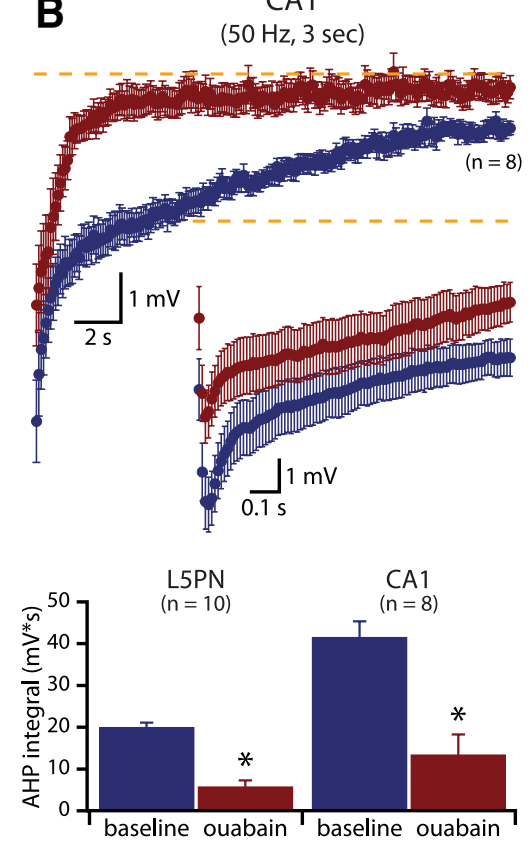

Figure 7. The sodium pump is the major contributor to the AHP. $A, B$, Population AHPs (resampled at $10 \mathrm{~Hz}$; mean \pm SEM) for L5PNs $(\boldsymbol{A})$ and CA1PNs $(\boldsymbol{B})$ in response to $50 \mathrm{~Hz}, 3$ s trains of action potentials under baseline conditions (blue), and after $120 \mathrm{~s}$ of focal application of ouabain ( $20 \mu \mathrm{m}$; red). In both neuron populations, ouabain reduced AHP peak amplitude (inset at $100 \mathrm{~Hz}$ ) and blocked the majority of the AHP. RMPs in baseline conditions were $-82 \pm 1 \mathrm{mV}$ and $-76 \pm 1 \mathrm{mV}$ for L5PNs and CA1PNs, respectively. After ouabain application, RMPs were $-80 \pm 1 \mathrm{mV}$ (L5PNs) and $-76 \pm 2 \mathrm{mV}$ (CA1PNs). C, Comparisons of the effects of ouabain on AHP peak amplitudes (left) and integrals (right) in L5PNs and CA1PNs. ${ }^{*} p<0.05$ compared with baseline (paired $t$ tests).

rons. In L5PNs, ouabain reduced AHP peak amplitudes from $6.8 \pm 0.2 \mathrm{mV}$ in baseline conditions to $5.3 \pm 0.4 \mathrm{mV}$ after ouabain application $(p<0.05)$, whereas AHP integrals were reduced from $20 \pm 1 \mathrm{mV} \cdot \mathrm{s}$ to $6 \pm 1 \mathrm{mV} \cdot \mathrm{s}(p<0.001)$. Similarly, in CA1PNs, baseline AHP amplitudes $(8.1 \pm 0.8$ $\mathrm{mV})$ and integrals $(42 \pm 4 \mathrm{mV} \cdot \mathrm{s})$ were significantly reduced by ouabain to $5.6 \pm 0.7(p<0.01)$ and $14 \pm 5 \mathrm{mV} \cdot \mathrm{s}(p<0.001)$, respectively (Fig. $7 C, D$ ). These effects of ouabain were not reversible within a 20 min wash period (Crambert et al., 2000).

\section{Activity-dependent somatic calcium and sodium dynamics during the AHP}

To observe activity-dependent changes in intracellular ion concentrations directly, we delivered spike trains to L5PNs (Fig. $8 A, B$ ) and CA1PNs (Fig. 8C,D) loaded with fluorescent indicators for either calcium (OGB1, $100 \mu \mathrm{M}$ ) or sodium (SBFI, $1 \mathrm{~mm}$ ). Trains of action potentials $(50 \mathrm{~Hz}, 3 \mathrm{~s})$ increased somatic calcium and sodium concentrations, as reflected by increases in OGB1 fluorescence (Fig. 8 $A, C$ ) and decreases in SBFI fluorescence (Fig. $8 B, D)$. After spike trains, activity-induced changes in fluorescence decayed exponentially, whereas AHPs were best fit with double-exponential functions. Increases in somatic calcium decayed rapidly, with mean time constants of $2.1 \pm 0.3 \mathrm{~s}$ in L5PNs ( $n=14$; Helmchen et al., 1996; Abel et al., 2004; Lee et al., 2005) and $2.8 \pm 0.5 \mathrm{~s}$ in CA1PNs $(n=6$; Jahromi et al., 1999). Conversely, sodium transients decayed slowly, with mean time constants of $13.8 \pm 1.6 \mathrm{~s}$ in L5PNs $(n=10 ; p<0.0001$, unpaired $t$ test vs L5PN calcium decay) and $10.0 \pm 1.3 \mathrm{~s}$ in CA1PNs $(n=13 ; p<$ 0.01 , unpaired $t$ test vs CA1 calcium decay). Calcium decay in both neuron types was significantly faster than the decay of the AHP, which had mean weighted time constants of $8.7 \pm 0.8 \mathrm{~s}$
(L5PNs) and $11.2 \pm 2.3 \mathrm{~s}$ (CA1PNs) during $\mathrm{Ca}^{2+}$ imaging and $11.6 \pm 3.0$ (L5PNs) and $9.2 \pm 2.3 \mathrm{~s}$ (CA1PNs) during $\mathrm{Na}^{+}$ imaging $(p<0.01$ for both cell types when comparing calcium decay with AHP decay, paired $t$ tests). Conversely, the decay of somatic sodium transients was similar to that of AHP decay in both cell types ( $p=0.58$ and 0.75 when comparing sodium decay with AHP decay in L5PNs and CA1PNs, respectively). These data are consistent with a sodium-dependent mechanism contributing to AHPs in L5PNs and CA1PNs.

\section{Physiological spike trains generate sodium-pump-dependent AHPs}

The results above confirm that trains of action potentials generate sodiumdependent AHPs in pyramidal neurons (Schwindt et al., 1988; Schwindt et al., 1989; Sanchez-Vives et al., 2000b; Franceschetti et al., 2003; Abolafia et al., 2011). We wondered whether similar sodiumdependent AHPs occur after more physiological patterns of activity. To test this hypothesis, we replayed in vitro a placespecific pattern of action potentials (15 action potentials over $345 \mathrm{~ms}$, average interspike frequency of $78 \pm 16 \mathrm{~Hz}$ ) recorded originally in a rat CA1 "place cell" as the animal traversed the cell-specific place field (Fig. 9A). Replay of the PCT in L5PNs $(n=12)$ or CA1PNs $(n=10)$ generated AHPs that persisted for many seconds, even when BAPTA $(10 \mathrm{~mm})$ was included in patch-pipettes to block intracellular calcium signaling (Fig. 9B,C). In L5PNs, amplitudes and integrals of PCT-induced AHPs were, respectively, $3.3 \pm 0.3 \mathrm{mV}$ and $3.8 \pm 0.5 \mathrm{mV} \cdot \mathrm{s}$ in control neurons $(n=12)$, and $2.7 \pm 0.3 \mathrm{mV}(p=0.12$, unpaired $t$ test vs control $)$ and $6.7 \pm 1.3 \mathrm{mV} \cdot \mathrm{s}$ ( $p=0.06$ vs control) in BAPTA-filled neurons $(n=11)$. In CA1PNs, chelation of intracellular calcium reduced AHP peak amplitudes from $1.6 \pm 0.2 \mathrm{mV}$ in control neurons $(n=10)$ to $1.0 \pm 0.1 \mathrm{mV}$ in BAPTA-filled neurons $(n=13 ; p<0.05)$, whereas AHP integrals were not significantly affected by intracellular BAPTA $(4.9 \pm 0.8 \mathrm{mV} \cdot \mathrm{s}$ vs $6.4 \pm 0.4 \mathrm{mV} \cdot \mathrm{s}$ for control and BAPTA-filled neurons, respectively; $p=0.15$ ). This selective effect of intracellular calcium-chelation on AHP peak amplitude, but not integral, in CA1PNs is consistent with our results from experiments using longer-duration spike trains to induce AHPs (compare with Figs. 1,4).

Are PCT-induced AHPs capable of inhibiting action potential generation? We tested the impact of PCTs on neuronal excitability by comparing responses to minimally suprathreshold current steps $(50 \mathrm{~ms}, \sim 0.5 \mathrm{~Hz}$ ) applied before and after replay of the PCT (Fig. 10). In all cells tested ( $n=10$ each for L5PNs and CA1PNs), PCT-induced AHPs inhibited action potential generation for many seconds. The mean time to the first action potential after the PCT was $7.1 \pm 0.5 \mathrm{~s}$ for CA1PNs and $6.5 \pm 0.4 \mathrm{~s}$ for L5PNs. To better quantify the time course of PCT-induced inhibition of neuronal excitability, we repeated experiments using higherintensity current injections such that action potentials were reliably generated on each test pulse, even after replay of the PCT (Fig. 11A). By measuring the latency of each action potential 
relative to the start of the current step (Fig. $11 B)$, we could plot the time course of PCT-induced inhibition (Fig. 11C). Replay of the PCT increased the latency to action potential generation for many seconds, and the time course of this inhibition was, for the most part, insensitive to intracellular BAPTA (10 mm). The exception was for the initial test pulse occurring $760 \mathrm{~ms}$ after the PCT. The inclusion of BAPTA in the patch-pipette increased, rather than decreased, the peak latency shift in L5PNs from $3.9 \pm 0.6 \mathrm{~ms}$ in control neurons $(n=12)$ to $5.9 \pm 0.6 \mathrm{~ms}$ in BAPTA-filled neurons $(n=10 ; p<0.001$, unpaired $t$ test). Conversely, in CA1PNs, the presence of intracellular BAPTA reduced the shift in spike latency for the first test pulse after the PCT from $9.3 \pm 1.7 \mathrm{~ms}$ in control neurons $(n=10)$ to $3.7 \pm 1.6$ $\mathrm{ms}$ in BAPTA-filled neurons $(n=12, p<$ 0.001; Fig. 11C). These opposing effects of BAPTA on PCT-induced inhibition at the earliest time point are consistent with the opposing effects of BAPTA on AHP peak amplitudes in L5PNs and CA1PNs (Figs. 1, 4, 9). However, except for this earliest time point, the time course of PCT-induced inhibition was largely independent of intracellular calcium chelation (Fig. 11C). These data demonstrate that short, physiologically relevant patterns of activity generate long-lasting and calcium-independent AHPs that reduce neuronal excitability for many seconds.

Does the sodium pump mediate PCTinduced AHPs? In both L5PNs $(n=12$; Fig. $12 A)$ and CA1PNs $(n=9$; Fig. $12 B)$, removal of extracellular potassium reversibly reduced the integrals of PCT-induced AHPs. In L5PNs, potassium removal reversibly reduced PCT-induced AHP integrals by $55 \pm 10 \%(p<0.05$, repeatedmeasures ANOVA), even as AHP peak amplitudes increased by $33 \pm 14 \%(p<$ $0.01)$. In CA1PNs, removal of potassium reversibly reduced PCT-induced AHP integrals by $54 \pm 16 \%(p<0.05)$, whereas peak amplitudes were not significantly affected $(p=0.27)$. Further, when suprathreshold current steps were applied before and after the PCT (as in Fig. 11), removal of extracellular potassium reversibly blocked PCT-induced shifts in spike latency in both neuron types (Fig. 12C). Together with our data from Figure 6, these results suggest that potassium conductances play a role during the initial $\sim 1$ s of the AHP (in both L5PNs and CA1PNs during AHPs generated by $50 \mathrm{~Hz}, 3$ s spike trains; Fig. 6), during the initial few hundred milliseconds of the AHP (in L5PNs during PCT-induced AHPs; Fig. 12A), or not at all (in CA1PNs during PCT-induced AHPs; Fig. 12B).

PCT-induced AHPs were also blocked by ouabain (Fig. 13). Although ouabain did not significantly reduce AHP peak amplitudes OGB1 (C) or SBFI (D).
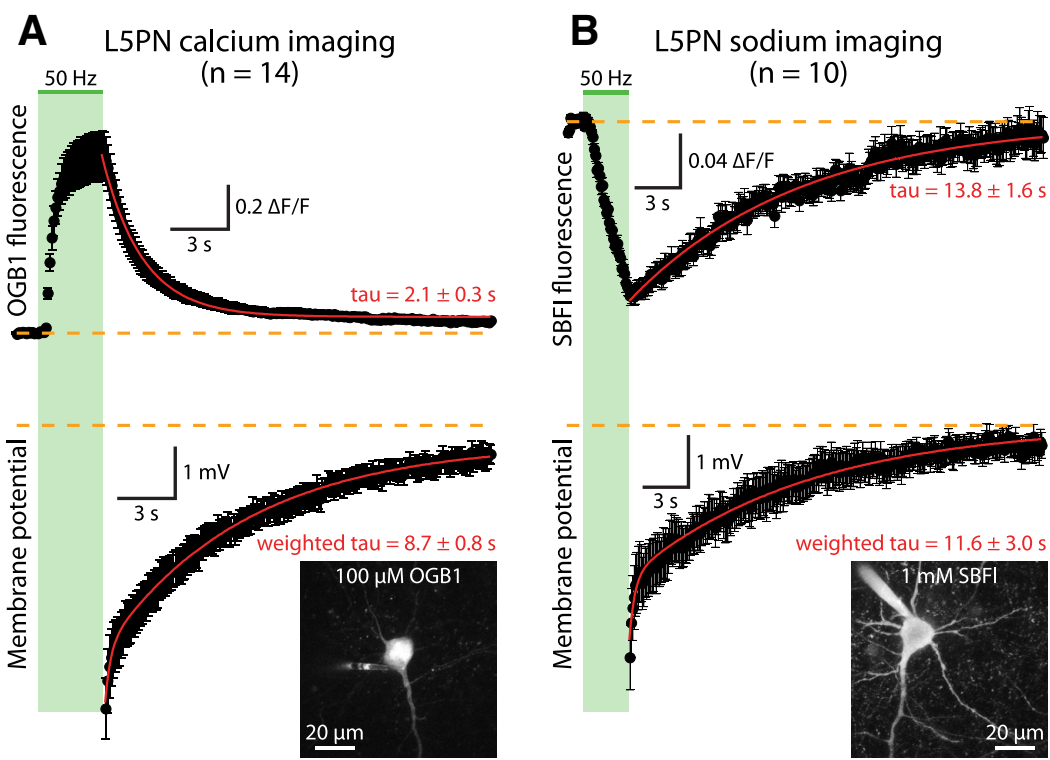

C CA1 calcium imaging
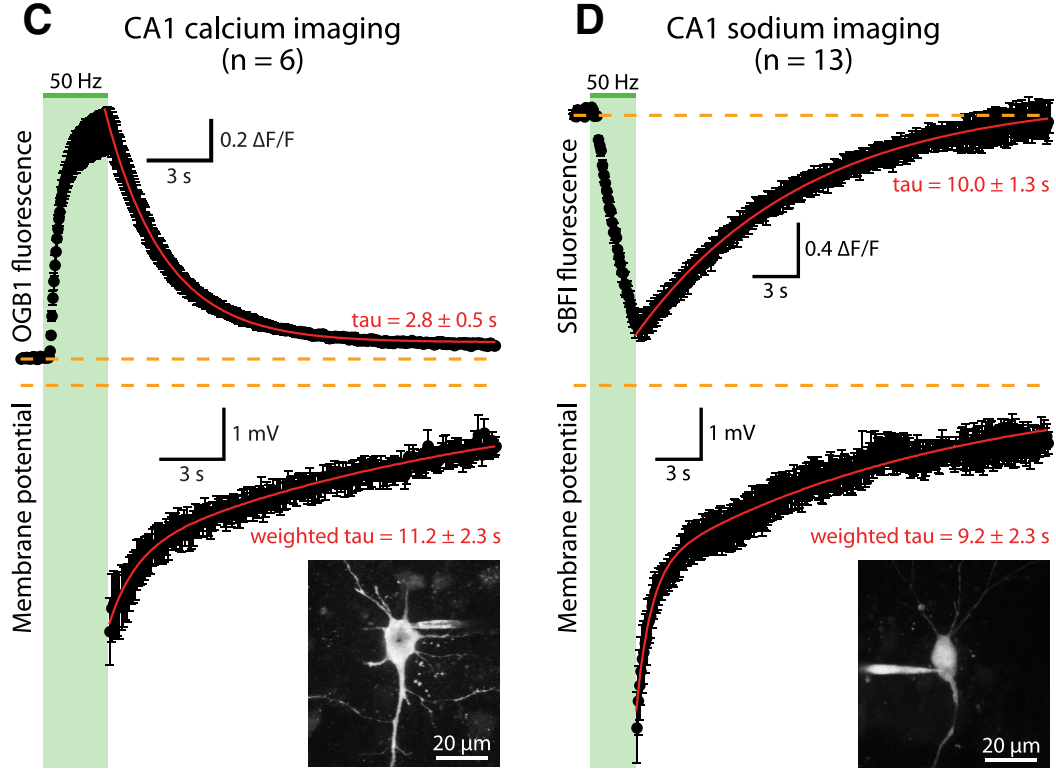

Figure 8. Time course of somatic sodium elimination reflects the time course of the AHP. $A, B$, Population optical (top) and electrical (bottom) responses (resampled at $10 \mathrm{~Hz}$; mean $\pm S$ EM for each point) to $50 \mathrm{~Hz}, 3$ s spike trains for $13 \mathrm{~L} 5 \mathrm{PNs}$ filled with the calcium-sensitive dye 0GB1 (100 $\mu \mathrm{m} ; \boldsymbol{A})$ and 10 L5PNs filled with the sodium indicator SBFI (1 mm; $\boldsymbol{B})$. AHPs were fit with double exponential functions, whereas decays in changes in fluorescence $(\Delta F / F)$ were fit with single exponential functions. Single and weighted-double exponential time constants shown as mean \pm SEM for each group, with best fits to the population data shown in red. Mean RMPs were $-75 \pm 2 \mathrm{mV}$ and $-79 \pm 1 \mathrm{mV}$ for OGB1-filled and SBFI-filled L5PNs, respectively. Insets: Images of L5PNs filled with OGB1 $(\boldsymbol{A})$ or SBFI $(1 \mathrm{~mm} ; \boldsymbol{B})$. $\boldsymbol{C}, \boldsymbol{D}$, Population calcium $(n=6)$ and sodium $(n=13)$ transients in CA1PNs, as revealed by changes in $0 G B 1(C)$ or $S B F I(D)$ fluorescence $(\Delta F / F)$ over time. Lower traces show population voltage responses to the $50 \mathrm{~Hz}$, 3 s spike train. Mean time constants for single (top) or weighted-double (bottom) exponential fits are indicated in red. Mean RMPs were $-76 \pm 1 \mathrm{mV}$ for OGB1-filled neurons and $-77 \pm 1 \mathrm{mV}$ for SBFI-filled neurons. Inset: Images of CA1PNs filled with

in L5PNs (Fig. 13A; $n=9 ; p=0.45$ ) or CA1PNs (Fig. $13 B ; n=7 ; p=$ $0.77)$, ouabain did reduce AHP integrals from $5.0 \pm 0.5 \mathrm{mV} \cdot \mathrm{s}$ to $0.8 \pm 0.3 \mathrm{mV} \cdot \mathrm{s}$ in L5PNs $(p<0.0001$, paired $t$ test $)$ and from $7.8 \pm$ $1.1 \mathrm{mV} \cdot \mathrm{s}$ to $1.5 \pm 0.5 \mathrm{mV} \cdot \mathrm{s}$ in CA1PNs $(p<0.01$, paired $t$ test). In L5PNs, ouabain also abolished the ability of PCT-induced AHPs to increase spike latency during suprathreshold current injections and ouabain had a similar effect on all but the initial test pulse (occurring $760 \mathrm{~ms}$ after the PCT) in CA1PNs (Fig. 13C). These data demonstrate a role for the sodium pump in regulating the excitability of pyramidal neurons after brief, physiologically relevant spike trains. 


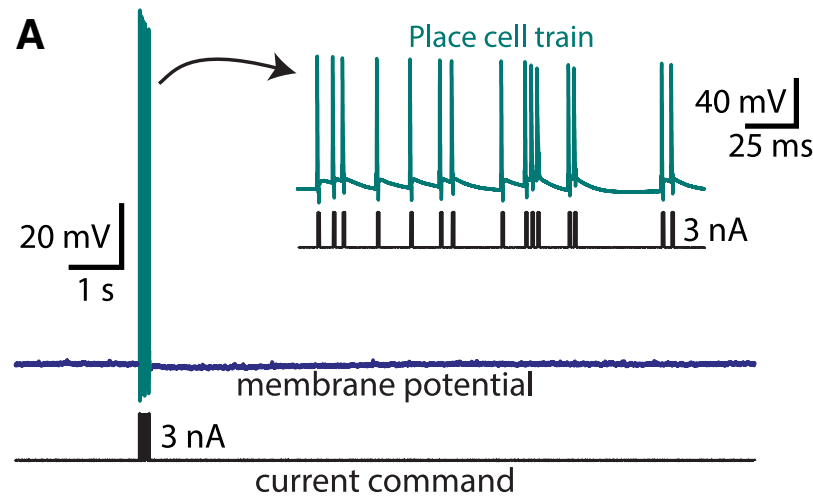

B

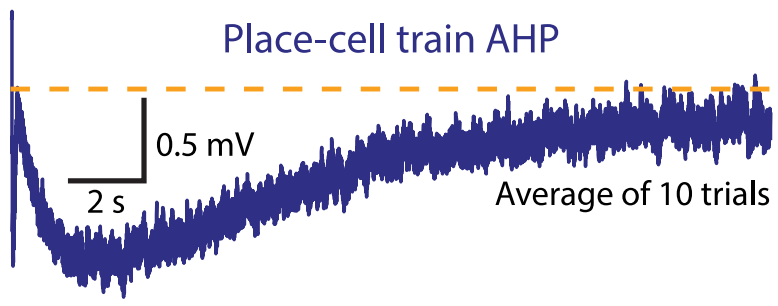

C

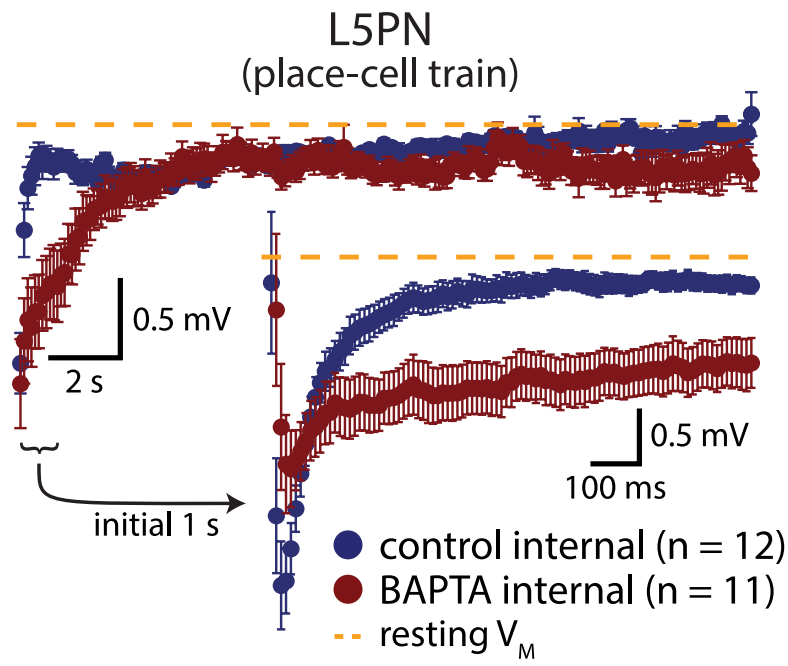

CA 1

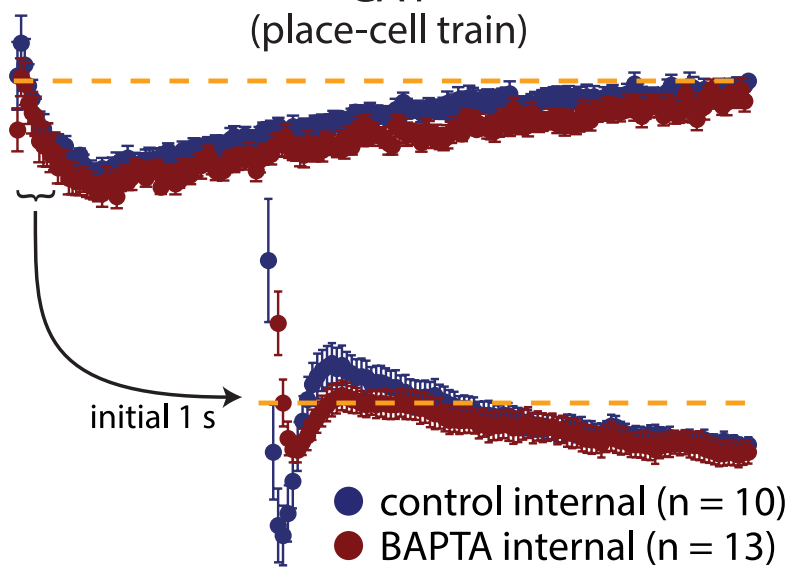

Figure 9. Calcium-independent AHPs generated by a physiological PCT. $A$, Current injections (bottom) reproducing in vitro a place-specific burst of action potentials originally recorded in a rat CA1 place cell in vivo. $B$, Average AHP generated by 10 trials in the CA1PN shown in A. C, Population AHPs (resampled at $10 \mathrm{~Hz}$; mean \pm SEM) generated by the PCT in L5PNs (top) or CA1PNs (bottom) in control conditions (blue) or in cells filled with $10 \mathrm{~mm}$ BAPTA (red). Mean RMPs were $-77 \pm 1 \mathrm{mV}$ (control) and $-77 \pm 1 \mathrm{mV}$ (BAPTA-filled)

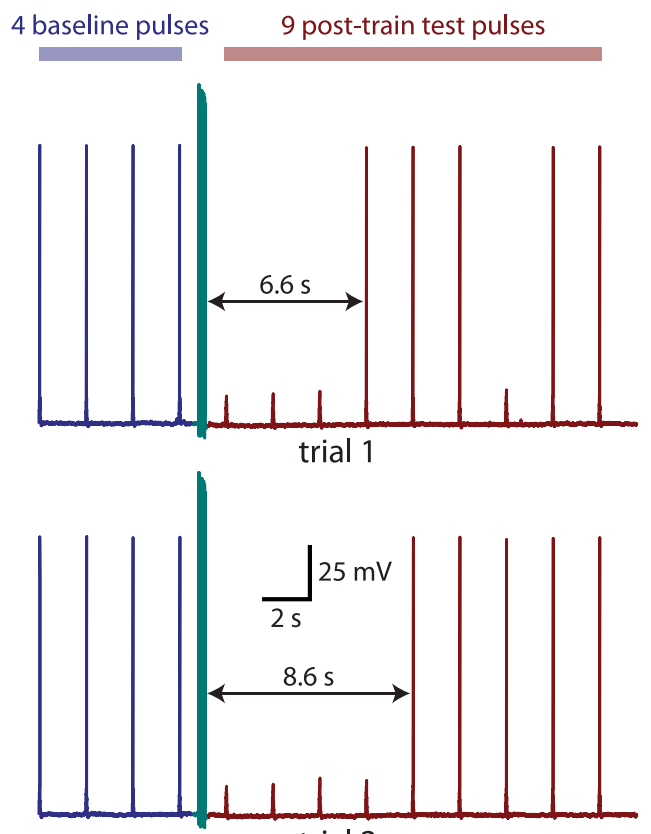

trial 2

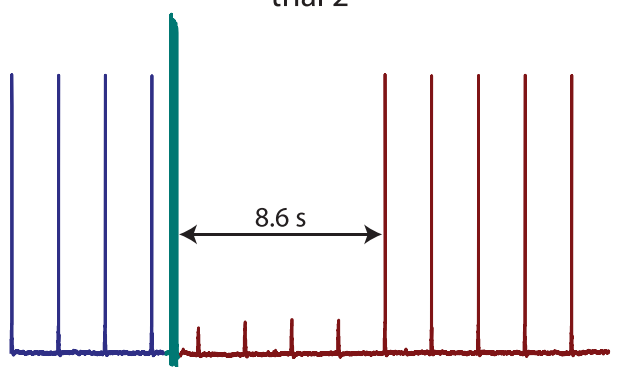

trial 3

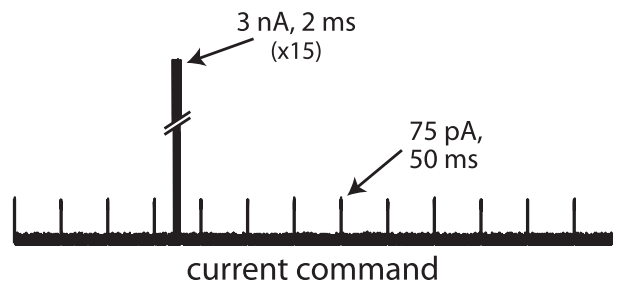

Figure 10. Physiological spike trains generate AHPs capable of reducing neuronal excitability for many seconds. Shown are three consecutive trials from an L5PN (RMP $=-83 \mathrm{mV})$ in which periodic, just-suprathreshold current injections ( $75 \mathrm{pA}$, $50 \mathrm{~ms}$ ) were applied before (blue) and after (red) replay of the PCT (green).

\section{Subphysiological temperatures reveal a calcium-dependent AHP}

If the sodium pump is primarily responsible for generating AHPs in pyramidal neurons, what accounts for the historical focus on calcium-activated potassium conductances? It is possible that differences in experimental design influence the mechanisms underlying the AHP. For example, AHP mechanisms could depend on animal species, animal age, and/or the temperature of neurons during experiments. In an earlier study, we noted nearly identical amplitudes and time courses of AHPs generated in CA1PNs from

$\leftarrow$

in L5PNs and $-74 \pm 2 \mathrm{mV}$ (control) and $-75 \pm 1 \mathrm{mV}$ (BAPTA-filled) in CA1PNs. Inset: Initial $1 \mathrm{~s}$ of the AHPs resampled at $100 \mathrm{~Hz}$. Cell-to-cell variability in the timing of the AHP peak in L5PNs generated population AHPs with smaller peak amplitudes than observed in individual neurons (see also Fig. 1C). Internal BAPTA only significantly reduced AHP peak amplitudes in CA1PNs. 
mice and rats (Dasari and Gulledge, 2011), and both calcium- and sodiumdependent AHPs have been observed in a variety of overlapping species (see Discussion). This suggests that AHP mechanisms are likely conserved in mammalian pyramidal neurons. Another possibility is that AHPs are developmentally regulated (Costa et al., 1992), because most studies focusing on calcium-dependent mechanisms have used neurons from immature ( $<4$ weeks old) animals (see Discussion), whereas studies reporting sodium-dependent AHPs in pyramidal neurons have generally used more mature neurons (Schwindt et al., 1989; Sanchez-Vives et al., 2000b; but see Franceschetti et al., 2003). However, when we compared AHPs generated in L5PNs and CA1PNs from 12- to 14-dold animals in control conditions ( $n=$ 11 for L5PNs, $n=9$ for CA1PNs) with AHPs generated in the presence of 200 $\mu \mathrm{M} \mathrm{Cd}^{2+}(n=11$ for L5PNs, $n=10$ for CA1PNs), we did not reveal additional calcium-dependent components of the AHP in neurons from young animals (Fig. 14). AHP peak amplitudes and integrals in L5PNs from young neurons in control conditions were $8.3 \pm 1.0 \mathrm{mV}$ and $38 \pm 7 \mathrm{mV} \cdot \mathrm{s}$, respectively (Fig. $14 A)$. In the presence of $\mathrm{Cd}^{2+}$, AHPs in L5PNs had amplitudes of $7.0 \pm 0.7 \mathrm{mV}$ ( $p=0.29$ compared with control, unpaired $t$ test) and integrals of $43 \pm 4 \mathrm{mV} \cdot \mathrm{s}$ ( $p=0.53$ compared with control). In CA1PNs from young animals (Fig. 14B), AHP amplitudes in control conditions and in the presence of $\mathrm{Cd}^{2+}$ were $5.3 \pm$ $0.3 \mathrm{mV}$ and $6.2 \pm 0.5 \mathrm{mV}$, respectively $(p=0.14)$, whereas AHP integrals were $36 \pm 3 \mathrm{mV} \cdot \mathrm{s}$ in control neurons and $33 \pm$ $4 \mathrm{mV} \cdot \mathrm{s}$ in the presence of $\mathrm{Cd}^{2+}(p=$ $0.57)$. Therefore, we found no significant calcium-dependent components to AHPs in L5PNs and CA1PNs from young (12- to 14-d-old) mice.

A third possibility is that temperature might affect the relative contribution of calcium-dependent mechanisms to the AHP (Gustafsson and Wigström, 1983). Indeed, the kinetics of the AHP are slower at low temperatures (Thompson et al., 1985; Sah and Isaacson, 1995; Lee et al., 2005), with Lancaster and Adams (1986) reporting a 4-fold increase in AHP decay rate when temperatures were raised from 27.5 to $32.5^{\circ} \mathrm{C}$. To test the impact of temperature on AHP mechanisms, we generated AHPs in response to $50 \mathrm{~Hz}, 3 \mathrm{~s}$ spike trains in L5PNs and CA1PNs at room temperature $\left(23^{\circ} \mathrm{C}\right)$, after heating to $35^{\circ} \mathrm{C}$, and again after cooling back to room tem-
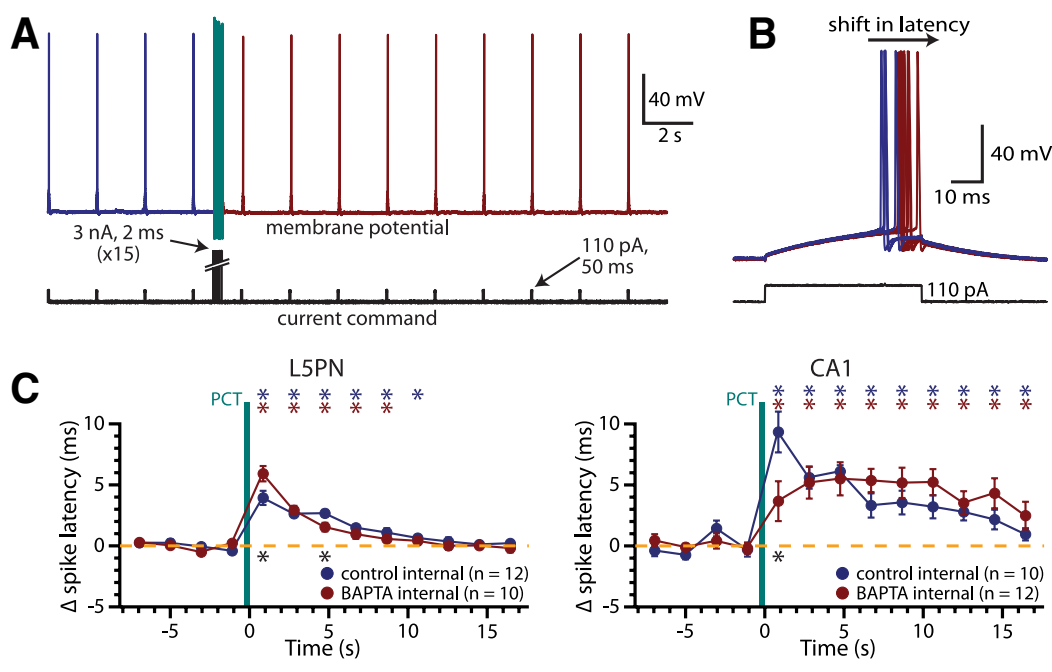

Figure 11. AHPs generated by physiological spike trains inhibit action potential generation for many seconds. $\boldsymbol{A}$, Current injections (bottom) were used to generated periodic single action potentials (at $\sim 2$ s intervals) and the PCT in a CA1PN (RMP $=$ $-77 \mathrm{mV}$ ). After 4 "baseline" current injections (blue), the cell experienced the PCT (green), followed by 9 additional periodic test current pulses (red). $\boldsymbol{B}$, Responses to test pulses in $\boldsymbol{A}$ expanded and superimposed. The PCT increased the latency to spike initiation during subsequent current injections. $C$, Plots of the mean ( \pm SEM) change in spike latency (relative to mean baseline latency) for action potentials generated before and after PCTs in L5PNs (left) and CA1PNs (right). Blue symbols indicate experiments using control intracellular solution, whereas red symbols indicate neurons in which $10 \mathrm{~mm}$ BAPTA was included in the patch-pipette. Significant $(p<0.05)$ changes in spike latency relative to baseline latencies are indicated by blue and red asterisks for control and BAPTA-filled neurons, respectively. Black asterisks indicate significant differences in the latencies between control and BAPTAfilled neurons.
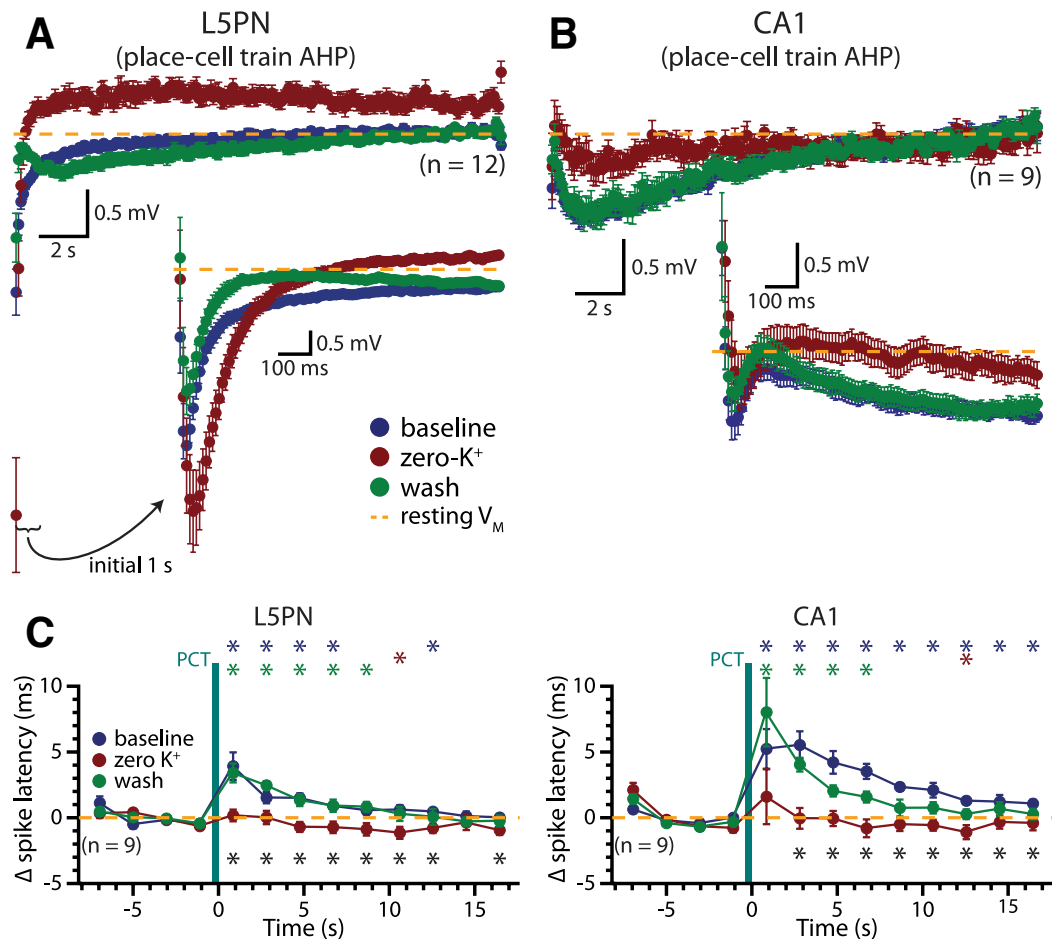

Figure 12. Removal of extracellular potassium blocks the slow-component of PCT-induced AHPs. $\boldsymbol{A}, \boldsymbol{B}$, Population AHPs (resampled at $10 \mathrm{~Hz}$; mean \pm SEM) for L5PNs $(\boldsymbol{A})$ and CA1PNs $(\boldsymbol{B})$ in response to the PCT under baseline conditions (blue), after $\sim 10$ min of exposure to potassium-free aCSF (red), and after 5 min of wash with regular aCSF (green). Inset: Initial $1 \mathrm{~s}$ of the population AHPs (100 Hz). Potassium-free aCSF reversibly inhibited the slow component of the AHP in both L5PNs (left) and CA1PNs (right). Mean RMPs in L5PNs and CA1PNs, respectively, were $-79 \pm 1 \mathrm{mV}$ and $-75 \pm 1 \mathrm{mV}$ in baseline conditions, $-80 \pm 1 \mathrm{mV}$ and $-77 \pm 1 \mathrm{mV}$ in zero-potassium conditions, and $-77 \pm 1 \mathrm{mV}$ and $-75 \pm 1 \mathrm{mV}$ in wash. C, Plots of changes in spike latency during test pulses delivered before and after the PCT (compare with Fig. 11) in L5PNs (left) and CA1PNs (right) in baseline conditions (blue), with potassium removed from the aCSF (red), and after potassium replacement (green). 
A

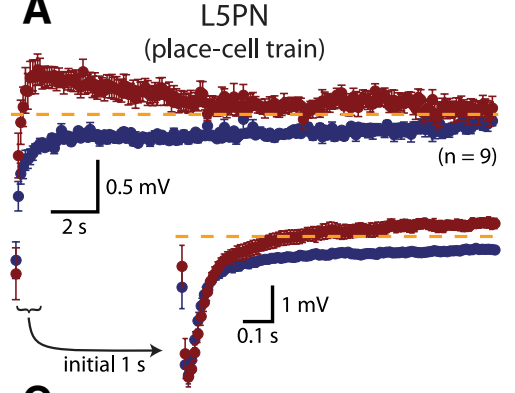

C

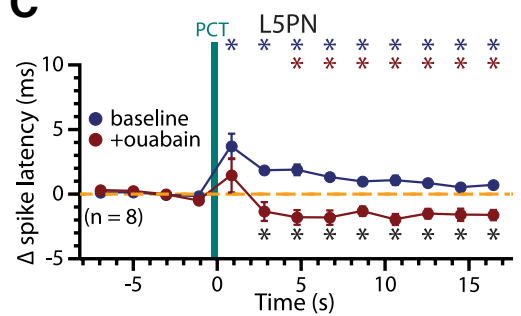

B
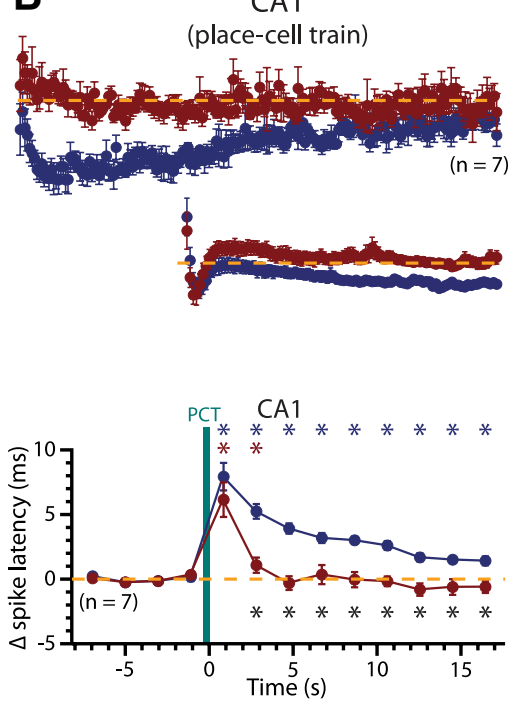

Figure 13. Ouabain blocks PCT-induced AHPs. $\boldsymbol{A}, \boldsymbol{B}$, Population AHPs in L5PNs $(\boldsymbol{A})$ and CA1PNs $(\boldsymbol{B})$ in response to the PCT in baseline conditions (blue) and after focal ouabain application ( $20 \mu \mathrm{m}$; red). Ouabain blocked all but the initial $100-200 \mathrm{~ms}$ of the AHP. Mean RMPs in L5PNs and CA1PNs, respectively, were $-83 \pm 1 \mathrm{mV}$ and $-79 \pm 1 \mathrm{mV}$ in baseline conditions and $-80 \pm 1$ $\mathrm{mV}$ and $-77 \pm 2 \mathrm{mV}$ in ouabain. C, Plots of relative spike latency (compare with Fig. 11) before and after presentation of the PCT in L5PNs (left) and CA1PNs (right) in baseline conditions (blue) and after application of ouabain (red).

A

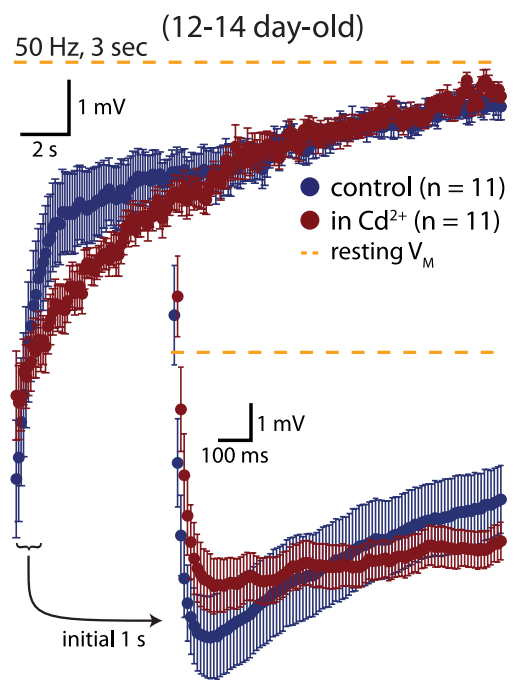

B

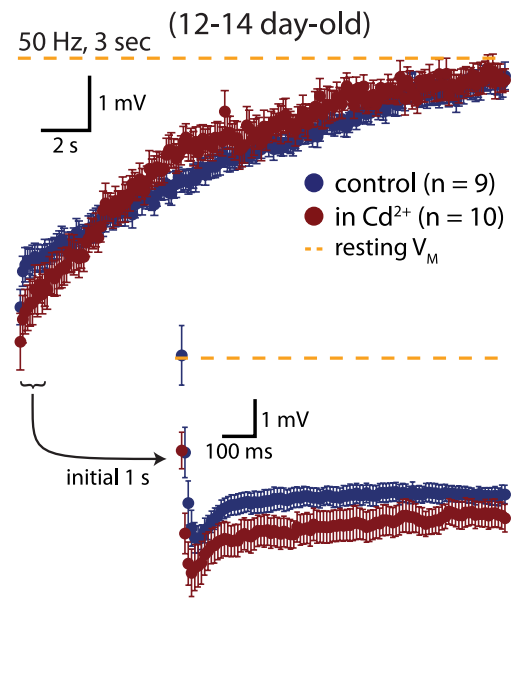

Figure 14. AHPs in pyramidal neurons from young (12- to 14-d-old) animals do not require calcium entry. $A, B$, Population AHPs (resampled at $10 \mathrm{~Hz}$ ) generated by $50 \mathrm{~Hz}$, 3 s trains of action potentials in L5PNs $(\boldsymbol{A})$ and $C A 1 P N s(B)$ from 12-to 14-d-old mice. Inset: Initial $1 \mathrm{~s}$ of the AHP resampled at $100 \mathrm{~Hz}$. Blue plots indicate data from control neurons ( $n=11$ for L5PNs, $n=9$ for CA1PNs) whereas red plots indicate neurons patched in the presence of $200 \mu \mathrm{M} \mathrm{Cd^{2+ }}$ ( $n=11$ for L5PNs, $n=10$ for CA1PNs). Mean RMPs in L5PNs and CA1PNs were, respectively, $-69 \pm 1 \mathrm{mV}$ and $-73 \pm 1 \mathrm{mV}$ in control conditions and $-71 \pm 1 \mathrm{mV}$ and $-69 \pm 1$ $\mathrm{mV}$ in the presence of $\mathrm{Cd}^{2+}$.

perature (Fig. 15A). AHPs generated at room temperature had significantly larger peak amplitudes and integrals than did AHPs generated at $35^{\circ} \mathrm{C}$. In L5PNs, AHP peak amplitudes and integrals were, respectively, $12.3 \pm 0.3 \mathrm{mV}$ and $37 \pm 1 \mathrm{mV} \cdot \mathrm{s}$ in baseline (room temperature) conditions, $7.6 \pm 0.4 \mathrm{mV}$ and $20 \pm 2 \mathrm{mV} \cdot \mathrm{s}$ when slices were heated to $35^{\circ} \mathrm{C}$, and $11.6 \pm 0.5 \mathrm{mV}$ and $44 \pm$ $4 \mathrm{mV} \cdot \mathrm{s}$ upon cooling back to room temperature $(n=5 ; p<0.01$ for amplitudes and $p<0.05$ for integral for AHPs at $35^{\circ} \mathrm{C}$, repeatedmeasures ANOVAs). Similarly, in CA1PNs, heating to $35^{\circ} \mathrm{C}$ reversibly reduced AHP amplitudes (from $9.9 \pm 0.9 \mathrm{mV}$ to $6.8 \pm 0.5 \mathrm{mV}$; $n=7 ; p<0.05$ ) and integrals (from $64 \pm 3$ $\mathrm{mV} \cdot \mathrm{s}$ to $36 \pm 2 \mathrm{mV} \cdot \mathrm{s} ; p<0.01)$, whereas cooling again to room temperature increased amplitudes $(8.9 \pm 0.1 \mathrm{mV})$ and integrals $(68 \pm 4 \mathrm{mV} \cdot \mathrm{s})$ to near-baseline values.

Are the larger AHPs occurring at room temperature reflective of calciumdependent processes? In additional groups of L5PNs and CA1PNs, we compared AHPs generated in control conditions at room temperature with those generated at room temperature in the presence of cadmium $(200 \mu \mathrm{M}$; Fig. $15 B)$. In control experiments conducted at $23^{\circ} \mathrm{C}$, AHP peak amplitudes were $12.4 \pm 0.4 \mathrm{mV}$ and $12.0 \pm 0.5 \mathrm{mV}$ for L5PNs $(n=7)$ and CA1PNs $(n=7)$, respectively. In neurons patched at room temperature in the presence of $\mathrm{Cd}^{2+}$, AHP amplitudes were significantly smaller, being $8.8 \pm 0.3 \mathrm{mV}$ and $6.9 \pm 0.6 \mathrm{mV}$, respectively, for L5PNs $(n=5)$ and CA1PNs ( $n=$ 6) $(p<0.0001$ for both neuron types in $\mathrm{Cd}^{2+}$ compared with control neurons, unpaired $t$ tests). Although $\mathrm{Cd}^{2+}$ did not affect total AHP integrals ( $p=0.12$ and 0.09 for L5PNs and CA1PNs, respectively), $\mathrm{Cd}^{2+}$ significantly reduced the area of the initial AHP. Integrals of the initial $4 \mathrm{~s}$ of the AHP were $22 \pm 1 \mathrm{mV} \cdot \mathrm{s}$ and $30 \pm 4 \mathrm{mV} \cdot \mathrm{s}$ in control L5PNs and CA1PNs, respectively, but only $12 \pm 0 \mathrm{mV} \cdot \mathrm{s}$ and $12 \pm 1 \mathrm{mV} \cdot \mathrm{s}$ in L5PNs and CA1PNs when patched in the presence of $200 \mu \mathrm{MCd}^{2+}(p<0.05$ for both L5PNs and CA1PNs, unpaired $t$ tests). No such impact of $\mathrm{Cd}^{2+}$ was observed on the initial integrals ( $4 \mathrm{~s})$ of AHPs in L5PNs ( $p=$ $0.18)$ or CA1PNs $(p=0.23)$ recorded at $35^{\circ} \mathrm{C}$ (compare Figs. $1,4,15$ ). Therefore, we conclude that, whereas calcium-dependent contributions to the AHP are prominent at room temperature, under more physiological conditions $\left(35^{\circ} \mathrm{C}\right)$ the AHP is mediated primarily by the sodium pump.

\section{Discussion}

The main finding of the present study is that the sodium-potassium ATPase ("sodium pump”) generates prolonged AHPs after periods of action potential generation in neocortical and hippocampal pyramidal neurons. AHPs generated at $35^{\circ} \mathrm{C}$ were mostly insensitive to manipulations of cytosolic calcium accumulation (Figs. 1, 4, 9), but were sensitive to blockade of sodium channels with TTX (Figs. 1, 4), removal of extracellular potassium (Figs. 6, 12), or the presence of ouabain (Figs. 7, 13). Our results show that activity-dependent recruitment of the sodium pump suppresses pyramidal neuronal excitability for many seconds. Because the sodium pump is expressed in all cells, we propose that it represents a fundamental intrinsic negative feedback mechanism to limit the excitability of many, if not most, neurons. Indeed, sodium-pump-mediated, activitydependent hyperpolarizations have been reported in Drosophila 
(Pulver and Griffith, 2010), leech (Baylor and Nicholls, 1969), frog (Zhang and Sillar, 2012), lamprey (Parker et al., 1996), and mammalian (Gustafsson and Wigström, 1981, 1983; Kim et al., 2007; Kim and von Gersdorff, 2012) neurons.

Sodium-dependent AHPs have been reported in neocortical pyramidal neurons, but have generally been ascribed to activation of sodium-dependent potassium conductances, rather than the sodium pump (Schwindt et al., 1988; Schwindt et al., 1989; Sanchez-Vives et al., 2000b; Franceschetti et al., 2003; Abolafia et al., 2011), based primarily on their reversal near the potassium equilibrium potential, and increased membrane conductance during the AHP. However, only two studies tested directly a role for the sodium pump, and reported inconclusive results after prolonged bath-application of low concentrations $(\leq 10 \mu \mathrm{M})$ of ouabain (Schwindt et al., 1988; Franceschetti et al., 2003). On the contrary, we observed dramatic changes in the AHP immediately after a 2-min-long focal application of $20 \mu \mathrm{M}$ ouabain (Figs. 7, 13) that produced little, if any, changes in resting membrane properties (Vaillend et al., 2002; Desfrere et al., 2009). Further, although the initial portion $(<1 \mathrm{~s})$ of the AHP reversed when neurons were held at very negative $(\sim-120 \mathrm{mV})$ membrane potentials, the majority of the AHP continued to be hyperpolarizing (Fig. 5). Finally, we observed that removal of extracellular potassium reduced, rather than enhanced, all but the initial portion of the AHP (Figs. 6, 12), a result inconsistent with activation of potassium conductances, but expected if AHPs depend upon sodium pump activation. Althugh our data do not rule out a role for sodiumdependent potassium conductances, especially during the initial second or two of the response, they strongly suggest that the sodium pump plays the dominant role in generating AHPs in cortical pyramidal neurons.

Does the sodium pump regulate neuronal excitability in vivo? We found that in vitro replay of a brief $(<350 \mathrm{~ms}), 15$-action-potential PCT recorded originally in vivo generated long-lasting, sodium-pump-dependent AHPs that reduced neuronal excitability for many seconds (Figs. 9, 10, 11). Because sodium-pump-dependent inhibition builds in proportion to spike frequency and number, it will likely shape the pattern of ongoing neuronal activity in vivo. For example, progressive activation of the sodium pump during periods of sensory-driven activity may contribute to sensory adaptation in the visual (Sanchez-Vives et al., 2000a) and auditory (Abolafia et al., 2011) cortices. In the hippocampus, activity-dependent engagement of the sodium pump might contribute to the observed asymmetry in CA1 place field firing, where increases in firing $\mathrm{mV}$ in CA1PNs.
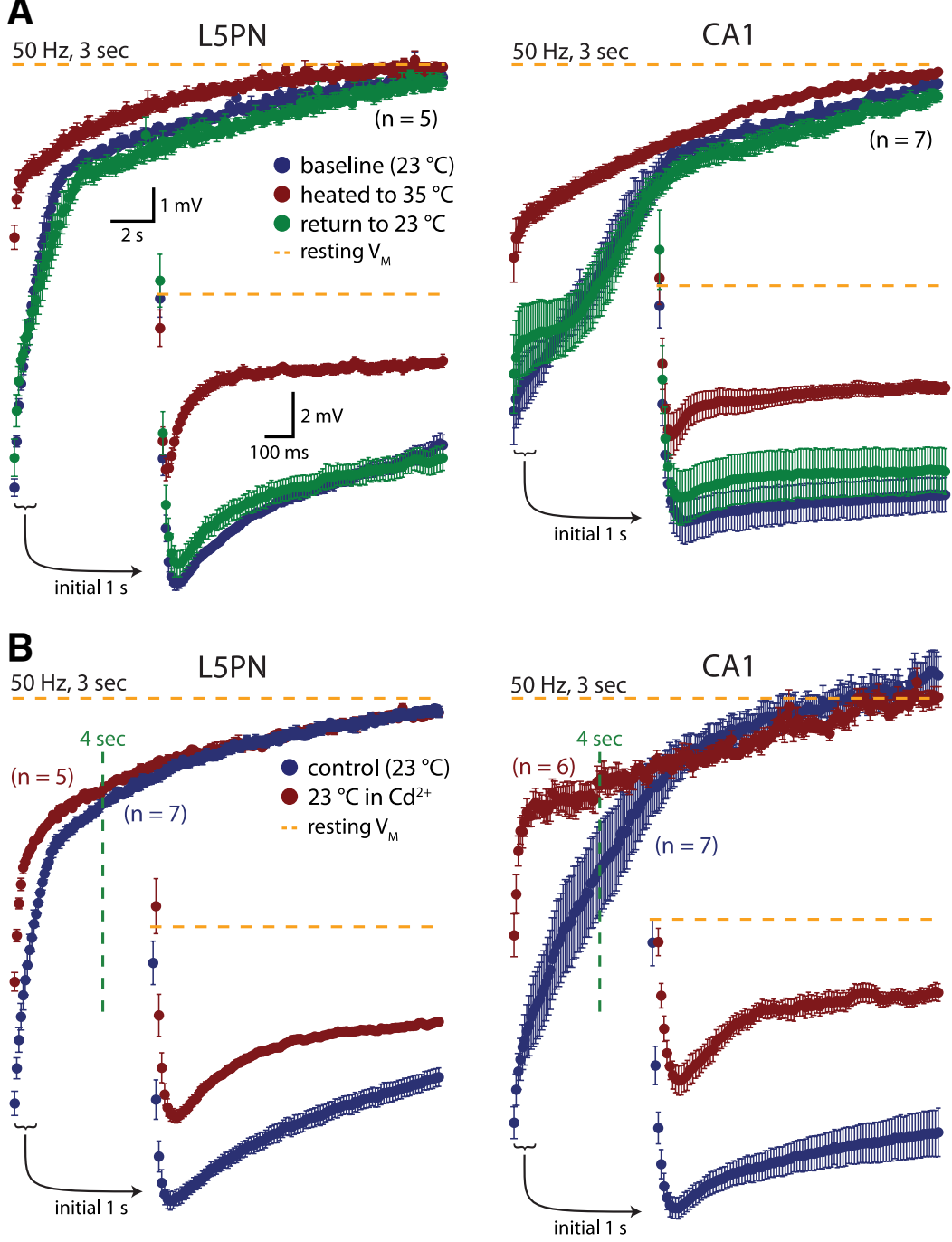

Figure 15. Calcium-dependent contribution to the AHP is temperature dependent. $A$, Population AHPs (resampled at $10 \mathrm{~Hz}$; mean \pm SEM) for L5PNs (left) and CA1PNs (right) recorded initially at room temperature $\left(23^{\circ} \mathrm{C}\right.$; blue), after warming to $35^{\circ} \mathrm{C}($ red), and after cooling again to room temperature (green). Inset: Initial $1 \mathrm{~s}$ of the AHP resampled at $100 \mathrm{~Hz}$. Increasing the temperature to $35^{\circ} \mathrm{C}$ reversibly reduced the amplitude of the initial few seconds of the AHP. L5PNs had RMPs of $-73 \pm 1 \mathrm{mV}$ in baseline room-temperature conditions, $-75 \pm 1 \mathrm{mV}$ at $35^{\circ} \mathrm{C}$, and $-73 \pm 1 \mathrm{mV}$ upon returning to room temperature. In CA1PNs, RMPs for each cell type) or in the presence of $200 \mu \mathrm{m} \mathrm{Cd}^{2+}$ (red; $n=5$ for L5PNs, $n=6$ for CA1PNs). Blockade of voltage-gated calcium abe $-74+1 \mathrm{mV}$ in $15 \mathrm{PN}$ s and $-70+1 \mathrm{mV}$ in CA1PNs. In the presence of $C \mathrm{~d}^{2+}$ RMPs were $-72+1 \mathrm{mV}$ in $15 \mathrm{PN}$ s and $-69+1$

rates as animals enter place fields are less abrupt than are decreases in firing as animals leave the same fields (Huxter et al., 2008). Consistent with these hypotheses, reduced sodium pump expression results in deficits in startle habituation (Kirshenbaum et al., 2011) and spatial learning (Moseley et al., 2007), suggesting that activity-dependent sodium pump currents may moderate neuronal excitability during behavior.

\section{Calcium versus sodium contributions to the AHP}

What explains the historical focus on calcium-dependent, rather than sodium-dependent, AHPs in pyramidal neurons? Three variables that might influence the ionic mechanisms mediating the AHP are animal species, animal age, and/or the temperature 
at which experiments are conducted. Calcium-dependent AHPs have been reported in pyramidal neurons in many mammalian species, including mice (Tzingounis et al., 2007), rats (Alger and Nicoll, 1980; Madison and Nicoll, 1982; Lancaster and Adams, 1986; Lancaster and Nicoll, 1987; Pedarzani and Storm, 1993; Zhang et al., 1994; Sah and Clements, 1999; Abel et al., 2004; Gerlach et al., 2004; Lima and Marrion, 2007), and guinea pigs (Hotson and Prince, 1980; Gustafsson and Wigström, 1981; Brown and Griffith, 1983; Thompson et al., 1985). Conversely, sodium-dependent AHPs in pyramidal neurons are reported here, in mice, and previously in rats (Abolafia et al., 2011), ferrets (Sanchez-Vives et al., 2000b), and cats (Schwindt et al., 1988; Schwindt et al., 1989). Given the lack of obvious speciesdelimited AHP mechanisms in prior studies, and our observations that AHPs in CA1PNs from mice and rats are similar in amplitude and time course (Dasari and Gulledge, 2011), it seems unlikely that AHP mechanisms are species specific.

Another possibility is that the mechanisms underlying the AHP are developmentally regulated (Costa et al., 1992). Because many prior studies have used tissue from animals younger than 4 weeks of age (Pedarzani and Storm, 1993; Sah and Clements, 1999; Lancaster et al., 2001; Abel et al., 2004; Gerlach et al., 2004; Lima and Marrion, 2007; Tzingounis et al., 2007), age-dependent changes in calcium-dependent and/or sodium-dependent processes might account for variability in AHP mechanisms. Indeed, sodium pump expression is upregulated in CA1PNs during the fourth to sixth postnatal weeks of life (Fukuda and Prince, 1992), and most prior observations of sodium-dependent AHPs in pyramidal neurons occurred in neurons from mature animals (Schwindt et al., 1988; Schwindt et al., 1989; Sanchez-Vives et al., 2000b; but see Franceschetti et al., 2003; Abolafia et al., 2011). However, we did not observe significant calciumdependent contributions to the AHP in pyramidal neurons from very young (12- to 14-d-old) animals (Fig. 14), suggesting that developmental changes are unlikely to explain differences in AHP mechanisms.

Temperature can also influence AHPs (Gustafsson and Wigström, 1983; Thompson et al., 1985; Lancaster and Adams, 1986; Sah and Isaacson, 1995; Lee et al., 2005). Similar to the results of Lee et al. (2005), we found that calcium-dependent contributions to the AHP were prominent at room temperature (Fig. 15), but largely absent at $35^{\circ} \mathrm{C}$. It is therefore noteworthy that many previous studies characterizing calcium-dependent AHPs in cortical neurons were conducted at or near room temperature $\left(\leq 26^{\circ} \mathrm{C}\right.$; Pedarzani and Storm, 1993; Zhang et al., 1994; Sah and Isaacson, 1995; Sah and Clements, 1999; Lancaster et al., 2001; Gerlach et al., 2004; Lima and Marrion, 2007; Tzingounis et al., 2007) and/or with limited heating $\left(28-32^{\circ} \mathrm{C}\right.$, Lancaster and Adams, $1986 ; 30^{\circ} \mathrm{C}$, Lancaster and Nicoll, $1987 ; 28-30^{\circ} \mathrm{C}$, Lancaster and Zucker, 1994, Sah and Isaacson, $1995 ; 28^{\circ} \mathrm{C}$, Lancaster et al., 2001). Conversely, experiments conducted at more physiological temperatures $\left(\geq 35^{\circ} \mathrm{C}\right)$ have preferentially observed sodiumdependent (Schwindt et al., 1988; Schwindt et al., 1989; SanchezVives et al., 2000b; Franceschetti et al., 2003), rather than calcium-dependent (Hotson and Prince, 1980) AHPs, with the duration of sodium-dependent AHPs ( $\sim 20$ s) tending to be an order of magnitude longer (but see Franceschetti et al., 2003) than AHPs triggered by calcium ( $\sim 1 \mathrm{~s}$; Hotson and Prince, 1980).

Finally, the historical focus on calcium-dependent mechanisms has led some investigators to routinely conduct measurements in the presence of TTX (Haas and Konnerth, 1983; Torres et al., 1995; Pedarzani and Storm, 1996; Pedarzani et al., 1998; Haug and Storm, 2000; Krause and Pedarzani, 2000; Tzingounis et al., 2007; Villalobos and Andrade, 2010; Villalobos et al., 2011), precluding observations of sodium-dependent contributions to the AHP (Figs. 3, 4). Accordingly, these studies have generally found AHPs to be of much shorter duration ( $\leq 3 \mathrm{~s}$ ) than reported here (but see Tzingounis et al., 2007). Alternatively, other studies may have taken for granted the role of calcium in generating AHPs, and did not test directly for ionic dependency (Thompson et al., 1985; Sah and Bekkers, 1996; Jahromi et al., 1999; Lee et al., 2005; Fernández de Sevilla et al., 2007; Gamelli et al., 2011). Our results, together with those of Schwindt et al. $(1988,1989)$ and Sanchez-Vives et al. (2000b), demonstrate that, at nearphysiological temperatures, the AHP is sodium dependent rather than calcium dependent. Our results go further by identifying the sodium pump, rather than potassium conductances, as the primary contributor to the AHP. Because the sodium pump is ubiquitous, intrinsically electrogenic, and responsive to changes in intracellular sodium, we propose that it represents a fundamental mechanism regulating neuronal excitability in many, if not most, neurons.

\section{References}

Abel HJ, Lee JC, Callaway JC, Foehring RC (2004) Relationships between intracellular calcium and afterhyperpolarizations in neocortical pyramidal neurons. J Neurophysiol 91:324-335. CrossRef Medline

Abolafia JM, Vergara R, Arnold MM, Reig R, Sanchez-Vives MV (2011) Cortical auditory adaptation in the awake rat and the role of potassium currents. Cereb Cortex 21:977-990. CrossRef Medline

Alger BE, Nicoll RA (1980) Epileptiform burst afterhyperolarization: calciumdependent potassium potential in hippocampal CAl pyramidal cells. Science 210:1122-1124. CrossRef Medline

Anderson TR, Huguenard JR, Prince DA (2010) Differential effects of $\mathrm{Na}+-\mathrm{K}+$ ATPase blockade on cortical layer V neurons. J Physiol 588: 4401-4414. CrossRef Medline

Andrade R, Foehring RC, Tzingounis AV (2012) The calcium-activated slow AHP: cutting through the Gordian knot. Front Cell Neurosci 6:47. CrossRef Medline

Baylor DA, Nicholls JG (1969) After-effects of nerve impulses on signalling in the central nervous system of the leech. J Physiol 203:571-589. Medline

Behr J, Gloveli T, Heinemann U (2000) Kindling induces a transient suppression of afterhyperpolarization in rat subicular neurons. Brain Res 867:259-264. CrossRef Medline

Brown DA, Griffith WH (1983) Calcium-activated outward current in voltage-clamped hippocampal neurones of the guinea-pig. J Physiol 337:287301. Medline

Chen X, Shu S, Bayliss DA (2005) Suppression of ih contributes to propofolinduced inhibition of mouse cortical pyramidal neurons. J Neurophysiol 94:3872-3883. CrossRef Medline

Costa PF, Santos AI, Ribeiro MA (1992) Slow and medium afterhyperpolarizations in maturing rat hippocampal CA1 neurones. Neuroreport 3:555558. CrossRef Medline

Crambert G, Hasler U, Beggah AT, Yu C, Modyanov NN, Horisberger JD, Lelièvre L, Geering K (2000) Transport and pharmacological properties of nine different human Na, K-ATPase isozymes. J Biol Chem 275:19761986. CrossRef Medline

Dasari S, Gulledge AT (2011) M1 and M4 receptors modulate hippocampal pyramidal neurons. J Neurophysiol 105:779-792. CrossRef Medline

Dasari S, Abramowitz J, Birnbaumer L, Gulledge AT (2013) Do canonical transient receptor potential channels mediate cholinergic excitation of cortical pyramidal neurons? Neuroreport 24:550-554. CrossRef Medline

Desfrere L, Karlsson M, Hiyoshi H, Malmersjö S, Nanou E, Estrada M, Miyakawa A, Lagercrantz H, El Manira A, Lal M, Uhlén P (2009) Na,KATPase signal transduction triggers CREB activation and dendritic growth. Proc Natl Acad Sci U S A 106:2212-2217. CrossRef Medline

Empson RM, Jefferys JG (2001) $\mathrm{Ca}(2+)$ entry through L-type $\mathrm{Ca}(2+)$ channels helps terminate epileptiform activity by activation of a $\mathrm{Ca}(2+)$ dependent afterhyperpolarisation in hippocampal CA3. Neuroscience 102:

297-306. CrossRef Medline 
Fernández de Sevilla D, Fuenzalida M, Porto Pazos AB, Buño W (2007) Selective shunting of the NMDA EPSP component by the slow afterhyperpolarization in rat CA1 pyramidal neurons. J Neurophysiol 97: 3242-3255. CrossRef Medline

Franceschetti S, Lavazza T, Curia G, Aracri P, Panzica F, Sancini G, Avanzini G, Magistretti J (2003) $\mathrm{Na}+$-activated $\mathrm{K}+$ current contributes to postexcitatory hyperpolarization in neocortical intrinsically bursting neurons. J Neurophysiol 89:2101-2111. Medline

Fukuda A, Prince DA (1992) Postnatal development of electrogenic sodium pump activity in rat hippocampal pyramidal neurons. Brain Res Dev Brain Res 65:101-114. CrossRef Medline

Gamelli AE, McKinney BC, White JA, Murphy GG (2011) Deletion of the L-type calcium channel $\mathrm{Ca}(\mathrm{V}) 1.3$ but not $\mathrm{Ca}(\mathrm{V}) 1.2$ results in a diminished sAHP in mouse CAl pyramidal neurons. Hippocampus 21:133-141. CrossRef Medline

Gerlach AC, Maylie J, Adelman JP (2004) Activation kinetics of the slow afterhyperpolarization in hippocampal CA1 neurons. Pflugers Arch 448: 187-196. CrossRef Medline

Gu N, Vervaeke K, Hu H, Storm JF (2005) Kv7/KCNQ/M and HCN/h, but not $\mathrm{KCa} 2 / \mathrm{SK}$ channels, contribute to the somatic medium afterhyperpolarization and excitability control in CA1 hippocampal pyramidal cells. J Physiol 566:689-715. CrossRef Medline

Gulledge AT, Park SB, Kawaguchi Y, Stuart GJ (2007) Heterogeneity of phasic cholinergic signaling in neocortical neurons. J Neurophysiol 97:2215-2229. CrossRef Medline

Gustafsson B, Wigström H (1981) Evidence for two types of afterhyperpolarization in CA1 pyramidal cells in the hippocampus. Brain Res 206:462-468. CrossRef Medline

Gustafsson B, Wigström H (1983) Hyperpolarization following longlasting tetanic activation of hippocampal pyramidal cells. Brain Res 275:159-163. CrossRef Medline

Haas HL, Konnerth A (1983) Histamine and noradrenaline decrease calcium-activated potassium conductance in hippocampal pyramidal cells. Nature 302:432-434. CrossRef Medline

Haug T, Storm JF (2000) Protein kinase A mediates the modulation of the slow $\mathrm{Ca}(2+)$-dependent $\mathrm{K}(+)$ current, $\mathrm{I}(\mathrm{sAHP})$, by the neuropeptides CRF, VIP, and CGRP in hippocampal pyramidal neurons. J Neurophysiol 83:2071-2079. Medline

Helmchen F, Imoto K, Sakmann B (1996) Ca2+ buffering and action potential-evoked $\mathrm{Ca} 2+$ signaling in dendrites of pyramidal neurons. Biophys J 70:1069-1081. CrossRef Medline

Hotson JR, Prince DA (1980) A calcium-activated hyperpolarization follows repetitive firing in hippocampal neurons. J Neurophysiol 43:409419. Medline

Huxter JR, Senior TJ, Allen K, Csicsvari J (2008) Theta phase-specific codes for two-dimensional position, trajectory and heading in the hippocampus. Nat Neurosci 11:587-594. CrossRef Medline

Jahromi BS, Zhang L, Carlen PL, Pennefather P (1999) Differential timecourse of slow afterhyperpolarizations and associated $\mathrm{Ca} 2+$ transients in rat CA1 pyramidal neurons: further dissociation by $\mathrm{Ca} 2+$ buffer. Neuroscience 88:719-726. CrossRef Medline

Kim JH, von Gersdorff H (2012) Suppression of spikes during post-tetanic hyperpolarization in auditory neurons: The role of temperature, Ih currents, and the $\mathrm{Na}+/ \mathrm{K}+$-ATPase pump. J Neurophysiol.

Kim JH, Sizov I, Dobretsov M, von Gersdorff H (2007) Presynaptic Ca2+ buffers control the strength of a fast post-tetanic hyperpolarization mediated by the alpha3 $\mathrm{Na}(+) / \mathrm{K}(+)$-ATPase. Nat Neurosci 10:196-205. CrossRef Medline

Kirshenbaum GS, Clapcote SJ, Duffy S, Burgess CR, Petersen J, Jarowek KJ, Yücel YH, Cortez MA, Snead OC 3rd, Vilsen B, Peever JH, Ralph MR, Roder JC (2011) Mania-like behavior induced by genetic dysfunction of the neuron-specific $\mathrm{Na}+, \mathrm{K}+$-ATPase alpha3 sodium pump. Proc Natl Acad Sci U S A 108:18144-18149. CrossRef Medline

Koike H, Mano N, Okada Y, Oshima T (1972) Activities of the sodium pump in cat pyramidal tract cell studied with intracellular injection of sodium ions. Exp Brain Res 14:449-462. Medline

Krause M, Pedarzani P (2000) A protein phosphatase is involved in the cholinergic suppression of the $\mathrm{Ca}(2+)$-activated $\mathrm{K}(+)$ current $\mathrm{sI}(\mathrm{AHP})$ in hippocampal pyramidal neurons. Neuropharmacology 39:1274-1283. CrossRef Medline

Lancaster B, Adams PR (1986) Calcium-dependent current generating the afterhyperpolarization of hippocampal neurons. J Neurophysiol 55: 1268-1282. Medline

Lancaster B, Nicoll RA (1987) Properties of two calcium-activated hyperpolarizations in rat hippocampal neurones. J Physiol 389:187-203. Medline

Lancaster B, Zucker RS (1994) Photolytic manipulation of Ca2 + and the time course of slow, $\mathrm{Ca}(2+)$-activated $\mathrm{K}+$ current in rat hippocampal neurones. J Physiol 475:229-239. Medline

Lancaster B, Hu H, Ramakers GM, Storm JF (2001) Interaction between synaptic excitation and slow afterhyperpolarization current in rat hippocampal pyramidal cells. J Physiol 536:809-823. CrossRef Medline

Lee JC, Callaway JC, Foehring RC (2005) Effects of temperature on calcium transients and $\mathrm{Ca} 2+$-dependent afterhyperpolarizations in neocortical pyramidal neurons. J Neurophysiol 93:2012-2020. Medline

Lima PA, Marrion NV (2007) Mechanisms underlying activation of the slow AHP in rat hippocampal neurons. Brain Res 1150:74-82. CrossRef Medline

Madison DV, Nicoll RA (1982) Noradrenaline blocks accommodation of pyramidal cell discharge in the hippocampus. Nature 299: 636-638. CrossRef Medline

Madison DV, Nicoll RA (1984) Control of the repetitive discharge of rat CA 1 pyramidal neurones in vitro. J Physiol 354:319-331. Medline

Moseley AE, Williams MT, Schaefer TL, Bohanan CS, Neumann JC, Behbehani MM, Vorhees CV, Lingrel JB (2007) Deficiency in Na,K-ATPase alpha isoform genes alters spatial learning, motor activity, and anxiety in mice. J Neurosci 27:616-626. CrossRef Medline

Moyer JR Jr, Thompson LT, Black JP, Disterhoft JF (1992) Nimodipine increases excitability of rabbit CA1 pyramidal neurons in an age- and concentration-dependent manner. J Neurophysiol 68:2100-2109. Medline

Parker D, Hill R, Grillner S (1996) Electrogenic pump and a Ca(2+)- dependent $\mathrm{K}+$ conductance contribute to a posttetanic hyperpolarization in lamprey sensory neurons. J Neurophysiol 76:540-553. Medline

Pedarzani P, Storm JF (1993) PKA mediates the effects of monoamine transmitters on the $\mathrm{K}+$ current underlying the slow spike frequency adaptation in hippocampal neurons. Neuron 11:1023-1035. CrossRef Medline

Pedarzani P, Storm JF (1996) Evidence that Ca/calmodulin-dependent protein kinase mediates the modulation of the $\mathrm{Ca} 2+$-dependent $\mathrm{K}+$ current, IAHP, by acetylcholine, but not by glutamate, in hippocampal neurons. Pflugers Arch 431:723-728. Medline

Pedarzani P, Krause M, Haug T, Storm JF, Stühmer W (1998) Modulation of the $\mathrm{Ca} 2+$-activated $\mathrm{K}+$ current sIAHP by a phosphatase-kinase balance under basal conditions in rat CA1 pyramidal neurons. J Neurophysiol 79:32523256. Medline

Pulver SR, Griffith LC (2010) Spike integration and cellular memory in a rhythmic network from $\mathrm{Na}+/ \mathrm{K}+$ pump current dynamics. Nat Neurosci 13:53-59. CrossRef Medline

Sah P, Bekkers JM (1996) Apical dendritic location of slow afterhyperpolarization current in hippocampal pyramidal neurons: implications for the integration of long-term potentiation. J Neurosci 16:4537-4542. Medline

Sah P, Clements JD (1999) Photolytic manipulation of [Ca2+]i reveals slow kinetics of potassium channels underlying the afterhyperpolarization in hippocampal pyramidal neurons. J Neurosci 19:3657-3664. Medline

Sah P, Isaacson JS (1995) Channels underlying the slow afterhyperpolarization in hippocampal pyramidal neurons: neurotransmitters modulate the open probability. Neuron 15:435-441. CrossRef Medline

Sanchez-Vives MV, Nowak LG, McCormick DA (2000a) Membrane mechanisms underlying contrast adaptation in cat area 17 in vivo. J Neurosci 20:4267-4285. Medline

Sanchez-Vives MV, Nowak LG, McCormick DA (2000b) Cellular mechanisms of long-lasting adaptation in visual cortical neurons in vitro. J Neurosci 20:4286-4299. Medline

Schwindt PC, Spain WJ, Foehring RC, Chubb MC, Crill WE (1988) Slow conductances in neurons from cat sensorimotor cortex in vitro and their role in slow excitability changes. J Neurophysiol 59:450-467. Medline

Schwindt PC, Spain WJ, Crill WE (1989) Long-lasting reduction of excitability by a sodium-dependent potassium current in cat neocortical neurons. J Neurophysiol 61:233-244. Medline

Schwindt PC, Spain WJ, Crill WE (1992) Calcium-dependent potassium currents in neurons from cat sensorimotor cortex. J Neurophysiol 67: 216-226. Medline

Storm JF (1987) Action potential repolarization and a fast after- 
hyperpolarization in rat hippocampal pyramidal cells. J Physiol 385:733759. Medline

Storm JF (1989) An after-hyperpolarization of medium duration in rat hippocampal pyramidal cells. J Physiol 409:171-190. Medline

Surges R, Freiman TM, Feuerstein TJ (2004) Input resistance is voltage dependent due to activation of Ih channels in rat CAl pyramidal cells. J Neurosci Res 76:475-480. CrossRef Medline

Thompson SM, Masukawa LM, Prince DA (1985) Temperature dependence of intrinsic membrane properties and synaptic potentials in hippocampal CA1 neurons in vitro. J Neurosci 5:817-824. Medline

Torres GE, Chaput Y, Andrade R (1995) Cyclic AMP and protein kinase A mediate 5-hydroxytryptamine type 4 receptor regulation of calciumactivated potassium current in adult hippocampal neurons. Mol Pharmacol 47:191-197. Medline

Tzingounis AV, Nicoll RA (2008) Contribution of KCNQ2 and KCNQ3 to the medium and slow afterhyperpolarization currents. Proc Natl Acad Sci U S A 105:19974-19979. CrossRef Medline

Tzingounis AV, Kobayashi M, Takamatsu K, Nicoll RA (2007) Hippocalcin gates the calcium activation of the slow afterhyperpolarization in hippocampal pyramidal cells. Neuron 53:487-493. CrossRef Medline

Vaillend C, Mason SE, Cuttle MF, Alger BE (2002) Mechanisms of neuronal hyperexcitability caused by partial inhibition of $\mathrm{Na}+-\mathrm{K}+$-ATPases in the rat CA1 hippocampal region. J Neurophysiol 88:2963-2978. CrossRef Medline

Villalobos C, Andrade R (2010) Visinin-like neuronal calcium sensor proteins regulate the slow calcium-activated afterhyperpolarizing current in the rat cerebral cortex. J Neurosci 30:14361-14365. CrossRef Medline

Villalobos C, Foehring RC, Lee JC, Andrade R (2011) Essential role for phosphatidylinositol 4,5-bisphosphate in the expression, regulation, and gating of the slow afterhyperpolarization current in the cerebral cortex. J Neurosci 31:18303-18312. CrossRef Medline

Wang YC, Huang RC (2006) Effects of sodium pump activity on spontaneous firing in neurons of the rat suprachiasmatic nucleus. J Neurophysiol 96:109-118. CrossRef Medline

Zhang HY, Sillar KT (2012) Short-term memory of motor network performance via activity-dependent potentiation of $\mathrm{Na}+/ \mathrm{K}+$ pump function. Curr Biol 22:526-531. CrossRef Medline

Zhang L, Weiner JL, Valiante TA, Velumian AA, Watson PL, Jahromi SS, Schertzer S, Pennefather P, Carlen PL (1994) Whole-cell recording of the $\mathrm{Ca}(2+)$-dependent slow afterhyperpolarization in hippocampal neurones: effects of internally applied anions. Pflugers Arch 426:247253. CrossRef Medline 